\title{
Critical Care for COVID-19 Affected Patients: Position Statement of the Indian Society of Critical Care Medicine
}

Yatin Mehta ${ }^{1}$, Dhruva Chaudhry ${ }^{2}$, OC Abraham ${ }^{3}$, Jose Chacko ${ }^{4}$, Jigeeshu Divatia ${ }^{5}$, Bharat Jagiasi ${ }^{6}$, Arindam Kar $^{7}$, GC Khilnani ${ }^{8}$, Bhuvana Krishna ${ }^{9}$, Prashant Kumar ${ }^{10}$, RK Mani ${ }^{11}$, BK Rao ${ }^{12}$, Pawan K Singh ${ }^{13}$, Sanjeev Singh ${ }^{14}$, Pavan Tiwary ${ }^{15}$, Chand Watta ${ }^{16}{ }^{16}$, Deepak Govil ${ }^{17}$, Subhal Dixit ${ }^{18}$, Srinivas Samavedam ${ }^{19}$

\author{
Abstract \\ The global pandemic involving severe acute respiratory syndrome-coronavirus-2 (SARS-COV-2) has stretched the limits of science. Ever since it \\ emerged from the Wuhan province in China, it has spread across the world and has been fatal to about $4 \%$ of the victims. This position statement \\ of the Indian Society of Critical Care Medicine represents the collective opinion of the experts chosen by the society. \\ Keywords: COVID-19, SARS-COV-2, Viral pneumonia. \\ Indian Journal of Critical Care Medicine (2020): 10.5005/jp-journals-10071-23395
}

\section{INTRODUCTION}

Corona virus disease (COVID-19), within a span of 3 months of its first appearance in Wuhan, China, in December 2019, has become a pandemic and is affecting the global healthcare system in an adverse manner. India successfully managed the initial phase of the epidemic with proactive public health measures but in spite of the best of efforts we are inching toward stage three of the illness, with more than 8,000 cases being positive so far. As Per the initial data, nearly $3-10 \%$ of the patients will require intensive care unit (ICU) admission. Given that the disease affects the airway and lung, and myocarditis at later stage, it would be prudent to prepare for the challenges ahead of us, especially when no definitive treatment or post exposure prophylaxis is available.

Ventilator management and hemodynamic monitoring will require significant step-up, while at the same time, measures to prevent further transmission and safeguard ourselves will also be a major challenge. Staff education and training are the most effective modalities to enhance ICU preparedness. This document is designed to provide an elaborate insight into the dos and don'ts while handling such patients.

\section{Methodology for Development of Position Statement}

The extraordinary circumstances which necessitated this position statement forced us to adopt a change to the Delphi method. The main constraints were time and inability to have a physical roundtable meeting. Therefore, a group of three experts was identified for each section and the core questions of that section were given to them. They exchanged views over e-mail and teleconferencing and arrived at a consensus. Their consensus statement was then submitted to the main author and the corresponding author. Changes were suggested where applicable and a final version was arrived at.

\section{Preparedness of the Intensive Care Unit Response Plan}

- Process for rapidly identifying and isolating patients i.e., traffic control bundling (TCB) of confirmed or suspected COVID-19
${ }^{1,17}$ Institute of Critical Care and Anesthesiology, Medanta:The Medicity, Gurugram, Haryana, India

${ }^{2,13}$ Department of Pulmonary and Critical Care, Pandit Bhagwat Dayal Sharma Post Graduate Institute of Medical Sciences, Rohtak, Haryana, India

${ }^{3}$ Infectious Disease Medicine, Christian Medical College, Vellore, Tamil Nadu, India

${ }^{4}$ Critical Care Medicine, Narayana Hrudyala, Bengaluru, Karnataka, India

${ }^{5}$ Critical Care and Anesthesia, Tata Memorial Center, Homi Bhabha National Institute, Mumbai, Maharashtra, India

${ }^{6}$ Department of Critical Care, Reliance Hospital, Navi Mumbai, Maharashtra, India

${ }^{7}$ CK Birla Hospitals; CMRI Institute of Critical Care; Indian Society of Critical Care Medicine; European Society of Intensive Care Medicine

${ }^{8}$ Department of Pulmonary, Critical Care and Sleep Medicine, PSRI Hospital, New Delhi, India

${ }^{9}$ Department of Critical Care Medicine, St. John's Hospital, Bengaluru, Karnataka, India

${ }^{10}$ Department of Anesthesiology, Pandit Bhagwat Dayal Sharma Post Graduate Institute of Medical Sciences, Rohtak, Haryana, India

${ }^{11}$ Critical Care and Pulmonology, Batra Hospital and Medical Research Centre, New Delhi, India

${ }^{12}$ Department of Critical care and Emergency Medicine, Sir Ganga Ram Hospital, New Delhi, India

${ }^{14}$ Amrita Institute of Medical Sciences, Ernakulam, Kerala, India; Amrita Hospitals, Faridabad, Haryana, India

${ }^{15}$ All India Institute of Medical Sciences, New Delhi, India

${ }^{16}$ Clinical Microbiology and Immunology, Sir Ganga Ram Hospital, New Delhi, India

${ }^{18}$ Department of Critical Care Medicine, Sanjeevan and MJM Hospital, Pune, Maharashtra, India

${ }^{19}$ Department of Critical Care, Virinchi Hospital, Hyderabad, Telangana, India

Corresponding Author: Dhruva Chaudhry, Department of Pulmonary and Critical Care, Pandit Bhagwat Dayal Sharma Post Graduate Institute

() The Author(s). 2020 Open Access This article is distributed under the terms of the Creative Commons Attribution 4.0 International License (https://creativecommons. org/licenses/by-nc/4.0/), which permits unrestricted use, distribution, and non-commercial reproduction in any medium, provided you give appropriate credit to the original author(s) and the source, provide a link to the Creative Commons license, and indicate if changes were made. The Creative Commons Public Domain Dedication waiver (http://creativecommons.org/publicdomain/zero/1.0/) applies to the data made available in this article, unless otherwise stated. 
should be in place, which should include clearly displayed signage posted at various places within the institute.

- First and second triage areas should be clearly designated and demarcated.

- Screening must begin in an outdoor triage before entering the emergency room (ER) area and triage must separate the clean area ("cold zone") from the contaminated ("hot zone").

- Those triaged to the COVID-19 area should be routed to the transit zone of the resuscitation area for evaluation and stabilization. Other cases must be directed to the clean zone separated from this zone.

- Transfer to isolation wards/ICUs dedicated to suspected or confirmed COVID patients are to be routed through the transition zone clearly delineated and separate from other clean zones.

- The zones should be separated by checkpoints. These routes are not to be taken by other nurses, physicians and other hospital staff.

- Cough, sneezing and respiratory etiquettes and hand hygiene protocols should be printed and displayed.

- Alcohol based hand sanitizer for hand hygiene should be available at each entrance and in all common areas.

- Facility should have a process to ensure that patients with confirmed or suspected COVID-19 are rapidly moved to either isolation facilities of designated ICUs or HDUs.

- All hospitals should ensure their staff are trained, equipped and capable of practices needed to contain it.

\section{Infection Prevention and Control Policies and Training for Healthcare Personnel (HCP) Regarding}

- How and to whom COVID-19 cases should be reported?

- Triage procedures including patient placement.

- How to perform hand hygiene and 5/6 moments of hand hygiene?

- How to disinfect all hospitals and "high-touch" surfaces in ICUs/ HDUs?

- Signs and symptoms of infection (COVID-19).

- How to safely collect a specimen?

- Correct infection control practices and personal protective equipment (PPE) use.

\section{Preparing Job Cards for New Staff Being Posted in ICUs/HDUs}

- Shift plan

- Care plan

- Hand offs

- Documentation

- Infection prevention

- Critical care procedures

- Psychology assessment and care

- Team building and unit meetings

- Inventory management

\section{ICU Admission and Infection Control Plan}

- If admitted, place a patient with known or suspected COVID-19 in a single-person room with the door closed. Preferably the patient should have a dedicated bathroom.

- Airborne infection isolation rooms (AllRs), if available, should be reserved for patients who will be undergoing aerosolgenerating procedures. of Medical Sciences, Rohtak, Haryana, India, Phone: +91 9991101616 , e-mail: dhruvachaudhary@yahoo.co.in

How to cite this article: Mehta Y, Chaudhry D, Abraham OC, Chacko J, Divatia J, Jagiasi B, et al. Critical Care for COVID-19 Affected Patients: Position Statement of the Indian Society of Critical Care Medicine. Indian J Crit Care Med 2020;24(4):222-241.

Source of support: Nil

Conflict of interest: None

- During times of limited access to respirators or face masks, facilities could consider having HCP remove only gloves (if used) and perform hand hygiene between patients with the same diagnosis (e.g., confirmed COVID-19) while continuing to wear the same eye protection equipment and respirator or face mask (i.e., extended use). Risk of transmission from eye protection equipment and face masks during extended use is expected to be very low.

- HCPs should strictly follow the basic infection control practices between patients (e.g., hand hygiene, cleaning, and disinfecting shared equipment).

- Limit transport and movement of the patients outside their room only for medically essential purposes.

- Consider providing portable X-ray/ultrasound/ECG equipment in patient cohort areas to reduce the need for patient transport.

- To the extent possible, patients with known or suspected COVID19 should be housed in the same room/unit for the duration of their stay in the facility to minimize room transfers.

- All nondedicated, nondisposable medical equipment used for patient care should be cleaned and disinfected according to the manufacturer's instructions and facility policies.

- Ensure that environmental cleaning and disinfection procedures are followed consistently and correctly.

- Routine cleaning and disinfection procedures [hospital-grade disinfectant $0.1 \%$ to $1 \%$ sodium hypochlorite or isopropyl alcohol at least $60 \%$ (preferably $70 \%$ ) to frequently touched surfaces or objects for appropriate contact times as indicated on the product's label] are appropriate for COVID-19 in healthcare settings, including those patient-care areas in which aerosolgenerating procedures are performed.

- Management of laundry, food service utensils, and medical waste should also be performed in accordance with routine procedures. It is prudent to have disposable trays and cutlery.

- Once the patient has been discharged or transferred, the HCPs, including environmental services personnel, should refrain from entering the vacated room until sufficient time has elapsed for enough air changes to remove potentially infectious particles.

- After this time has elapsed, the room should undergo appropriate cleaning and surface disinfection before it is returned to routine use.

\section{Take-home Points}

- Identification of area for admitting COVID-19 patients with clear entry and exit points

- Identification of staff 
- Having thorough infection control policies

- Training of staff regarding correct use of PPE and in other areas of management

- Conduct mock drills

- Inventory checklist and procurement

\section{Staff and Institutional Capacity}

- Workforce alignment

- Staff illness and quarantine

- Alternative strategies during shortage of staff

\section{Workforce Alignment}

- Hospital should identify an ICU to provide care to COVID-19 suspected/confirmed cases, rather than accepting them in every ICU.

- Staff selected for COVID patient care should not have comorbidities or risk factors which are likely to make them susceptible to severe disease.

- Staff should be made aware of the risk of infection and infection control practices to be followed on such patients.

- Adequate staff strength should be provided in ICU to prevent long working hours and exhaustion.

- Ancillary staff such as those working at imaging services and microbiology should be made aware of such patients in advance to allow the staff to take precautions while the patients or their samples are with them.

- Deployment of staff from sanitation department should be increased to ensure environmental cleaning at least 3 times a day.

\section{Staff Illness and Quarantine}

- All staff members who are exposed to confirmed case of COVID19 should be reported to the management for exposure risk management.

- Staff having fever or respiratory symptoms should immediately report for checkup and should be taken off ICU duty.

\section{Alternative Strategies during Shortage of Staff}

- Hospitals should identify staff who can be mobilized from other ICUs or wards.

- Screening of this reserve staff should be done in advance.

- If there is a surge in COVID-19 cases, an alternative ICU or makeshift ICU can be commissioned for this purpose.

- The hospital should arrange to transfer such patients to a suitable preidentified facility if the surge is beyond the hospital's capacity.

\section{Take-home Points}

- Right staff at the right time

- Scheduling shifts in synchronization with routine traffic

- Alternative plan in case of staff shortage

- Protection of staff is of utmost importance

- Staff illness and quarantine.

\section{Training and Healthcare Worker Assurance}

- Basic care

- Ventilator strategies

\section{Basic Care}

In the current COVID-19 pandemic, approximately 10 to $20 \%$ patients require ICU admission and 3 to $10 \%$ patients require intubation and mechanical ventilation. When there is a shortage of trained staff (doctors, nurses, respiratory therapists, etc.), staff will need to be recruited from other areas and trained to take care of patients in the ICU, including provision of mechanical ventilation.

- Some of the staff may have received prior formal training in intensive care, whereas some would have been exposed to ICU protocols in their rotations. Such staff must be identified and trained in advance.

- Other staff such as anesthesiologists, internists, and other medical and nursing staff may be required to perform ICU duties and also perform specialized procedures such as tracheal intubation, central venous and arterial access, etc., during the pandemic.

\section{Tiered Staffing}

Tiered staffing with critical care staff collaborating with noncritical care staff for care of all ICU patients is a viable option. Noncritical care nurses may be assigned primary responsibilities for activities including patient assessment, documentation, administration of medications, and general care. Critical care nurses can supervise and advise noncritical care nurses on issues such as vasopressor and sedation titration. For example, one non-ICU nurse may look after two patients, and an ICU nurse can supervise two to three such nurses. Thus, one experienced ICU nurse can look after six patients. One nonintensivist can look after four to six patients and one intensivist can supervise four nonintensivists. Thus, one intensivist can manage up to 24 patients.

\section{Protocols}

All supportive care, ventilator care, hemodynamic support, etc., should be protocolized. These protocols should be available at the bedside and should be followed. The protocols should be based on the standard guidelines (such as the Surviving Sepsis Campaign guidelines) and institutional practice. An example of lung-protective ventilation is shown in Table A3.1.

\section{Education}

The ICU staff should have access to educational material in the form of slide shows presented by experts; videos from the websites of professional societies or journals and should be provided on-thespot training by other trained personnel present and mock drills.

\section{Quality Assurance}

Every attempt should be made to provide high-quality care during the pandemic, even in the absence of adequate numbers of trained healthcare providers. A trained practitioner can supervise several other staff members. This can be done in the ICU or remotely by audio or video phone call or telemedicine. 
Debriefing at the end of each shift is useful in discussing the problems and potential solutions.

\section{Ventilation Strategies \\ Ventilation Protocol for Patients with Acute Respiratory Distress Syndrome}

All patients who present with acute breathlessness ( $<7$ to 10 days) and having all of the following:

- $\mathrm{PaO}_{2} / \mathrm{FiO}_{2} \leq 300$ (corrected for altitude)

- Bilateral (patchy, diffuse, or homogeneous) infiltrates consistent with pulmonary edema

- No clinical evidence of left atrial hypertension/left heart failure

are diagnosed with acute respiratory distress syndrome (ARDS)/ SARI (severe acute respiratory illness). Ventilation strategies will primarily depend upon the severity of SARI/ARDS. The severity of ARDS is defined as:

- $\operatorname{Mild}\left(\mathrm{PaO}_{2} / \mathrm{FiO}_{2} \leq 300 \geq 200\right)$

- Moderate $\left(\mathrm{PaO}_{2} / \mathrm{FiO}_{2} \leq 200 \geq 100\right)$

- Severe $\left(\mathrm{PaO}_{2} / \mathrm{FiO}_{2} \leq 100\right)$

Some patients may have normal lungs to begin with but during the course of ICU treatment may develop more severe changes. Patients should be ventilated with ARDS net protocol. Therefore, remember never use large tidal volumes (VTs) for the ICU patients, always stay below $6 \mathrm{~mL} / \mathrm{kg}$ predicted body weight (PBW). Noninvasive ventilation in select patients with mild ARDS may be tried but have a low threshold for early intubation. Intubate the patient (while taking utmost aerosol precautions) preferably with an endotracheal (ET) tube with subglottic suction. Bag mask ventilation be avoided.

\section{Ventilator Setup and Adjustment}

- Calculate PBW.

- Males $=50+2.3$ [height (inches)-60].

- Females $=45.5+2.3$ [height (inches)-60].

- Select volume A/C mode on the ventilator.

- Set ventilator settings to achieve initial VT $=6 \mathrm{~mL} / \mathrm{kg}$ PBW.

- Set initial rate to approximate baseline minute ventilation (not $>35$ bpm). Aim for a pH over 7.2, do not worry about the $\mathrm{PaCO}_{2}$. If the $\mathrm{PaCO}_{2}$ keeps going up too much in spite of a respiratory rate (RR) of 35 , reduce the dead space in the circuit. If the $\mathrm{pH}$ drops below 7.2, consider adding sodium bicarbonate infusion.

- Adjust VT and RR to achieve $\mathrm{pH}$ and plateau pressure goals as mentioned below.

\section{Oxygenation Goal: $\mathrm{PaO}_{2} 55-80 \mathrm{~mm} \mathrm{Hg}$ or Oxygen Saturation} $\left(\mathrm{SpO}_{2}\right)$ 88-95\%

- Use a minimum positive end expiratory pressure (PEEP) of $5 \mathrm{~cm}$ $\mathrm{H}_{2} \mathrm{O}$. Consider the use of incremental $\mathrm{FiO}_{2} /$ PEEP combinations as shown below to achieve the goal.

- Plateau pressure goal: $\leq 30 \mathrm{~cm} \mathrm{H}_{2} \mathrm{O}$

- Check Pplat ( 0.5 second inspiratory pause) at least every 4 hours and after each change in PEEP or VT.

- If the Pplat remains above $30 \mathrm{~cm} \mathrm{H}_{2} \mathrm{O}$, decrease VT by $1 \mathrm{~mL} / \mathrm{kg}$ steps (minimum $=4 \mathrm{~mL} / \mathrm{kg}$ ).

\section{Oxygen Supply and Ventilators}

In the event of a large number of patients developing respiratory failure, the existing ICU beds are likely to be overwhelmed.
Operation theaters, post-anesthesia care unit beds, emergency department critical care beds, and monitored beds in endoscopy suites can be used to create additional ICU beds. These areas have the advantage of having facilities for oxygen, suction, and monitoring. If ventilation is needed for two adjacent patients and if only one oxygen port is available, convert a singly oxygen supply to dual by using the " $Y$ " connector at the outlet or preferably use an oxygen cylinder.

\section{Oxygen Supply}

Oxygen supply can be a problem outside of these areas. Liquid oxygen has a large capacity, and, if available, is the best option subject to regular refilling of the tank by the distributor. It is possible that the hospital oxygen supply may be inadequate to support large surges in mechanical ventilation. Oxygen cylinders can be sourced from operation theaters and other areas of the hospital but are likely to run out rapidly if large numbers of patients require mechanical ventilation with a high $\mathrm{FiO}_{2}$. Portable oxygen concentrators may be used for supplemental oxygen therapy.

\section{Alternatives to Ventilators}

Demand for ventilators may exceed the ventilators available in the ICU.

Noninvasive ventilators (NIVs) can be used for patients not requiring high $\mathrm{FiO}_{2}$ and for recovering patients, so that the highperformance ICU ventilators can be preserved for sicker patients. Transport ventilators can also be included in the inventory. Home NIVs and high-flow nasal cannula (HFNC) devices can play an important role in cases with mild severity of disease.

In addition, ancillary equipment such as ventilator circuits, humidification devices, closed suction catheter systems, and suction equipment must also be procured. A heat and moisture exchanger (HME) is ideal as it provides humidification and serves as a bacterial-viral filter.

\section{Isolation Precautions}

- Follow the standard infection control precautions for all patients, with additional contact and droplet isolation precautions for patients with COVID-19 admitted to the ICU (mandatory).

- Hand hygiene must be performed by all staff in accordance with World Health Organization's (WHO's) "5 Moments of Hand Hygiene" (mandatory). Before performing hand hygiene:

- Expose forearms

- Remove all hand and wrist jewelry and accessories

- Ensure finger nails are clean and short

- Cover all cuts/abrasions with waterproof dressing.

- Patient placement:

- Patients with COVID-19 (proven and suspected) should be admitted to an ICU designated for the same, with dedicated staff.

- Staff to stay in the ICU for the entire shift

- Spatial separation of at least $1 \mathrm{~m}$ between patient beds (mandatory)

- Thorough cleaning and disinfection of the environment and equipment per institutional policy (mandatory)

- Limit transport of patients outside the ICU (mandatory)

- Avoid/limit aerosol generating procedures [e.g., intubation, extubation, cardiopulmonary resuscitation (CPR) before intubation, bronchoscopy, NIV, tracheostomy, etc.]; if 
they are essential, airborne isolation precautions to be followed

- Restricted entry of staff to the designated ICU for COVID-19 patients, so that only those directly involved in patient care are provided entry

- Limit visitors to the ICU where COVID-19 patients are admitted (mandatory)

- Air-handling systems delivering $>12$ air changes per hour that are installed and properly maintained (desirable)

- Training all staff in infection control precautions and appropriate use of PPE (mandatory).

\section{Take-home Points}

- Tiering of staff

- Lung protective ventilation strategy

- Plan for mobilizing more ventilated beds in case of shortage of ventilators

- Judicious use of NIV/HFNC in mild and recovering cases to compensate for shortage of ventilators

- Isolation precautions to prevent cross infection to other patients.

\section{Critical Care Triage and Allocation}

- Admission criteria: different levels

- Discharge criteria: from ICU

- Managing other patients simultaneously

\section{General Triaging}

- All COVID-19 suspect patients coming to hospital should undergo triaging. The aim of triage is to segregate the patients who will require admission or evaluation. Also it decides which patients will need admission to ICUs or HDUs.

\section{Treatment triage for COVID 19 positive patients}

COVID 19 suspect with severe breathlessness

\begin{tabular}{|c|c|}
\hline $\begin{array}{l}\text { RR }>20 / M I N \\
\text { SpO } 2<92 \% \\
\text { qSOFA }>2\end{array}$ & \\
\hline \multicolumn{2}{|c|}{ Oxygen therapy (Maintain $\mathrm{SpO} 2>95 \%$ ) } \\
\hline$\downarrow$ & $\nabla$ \\
\hline$>150$ & $<150$ \\
\hline Noninvasive options & Invasive options \\
\hline $\begin{array}{l}\text { - HFNC } \\
\text { - NIV } \\
\text { Helmet interface better } \\
\text { - Awake proning }\end{array}$ & $\begin{array}{l}\text { - Lung protective } \\
\text { strategy with } \\
\text { early prone } \\
\text { ventilation }\end{array}$ \\
\hline
\end{tabular}

\section{Criteria for ICU Admission}

- Need for mechanical ventilation.

- Need for vasopressors.

- Respiratory rate $>25$ breaths per minute.

- $\mathrm{PaO}_{2}<50 \mathrm{~mm} \mathrm{Hg}$ on room air or $\mathrm{SpO}_{2}<90 \%$ on supplemental oxygen of $6 \mathrm{Lpm}$.

- Confusion.

- Leukopenia.
- Thrombocytopenia.

- Uremia.

- Multilobar infiltrates.

- Hypotension requiring fluid resuscitation.

- Hypothermia.

- quick sequential organ failure assessment (qSOFA) $>2$.

\section{Thresholds for Transfer of Deteriorating Cases for Extracorporeal Membrane Oxygenation (ECMO)}

- Severe hypoxemia $\left(\mathrm{PaO}_{2} / \mathrm{FiO}_{2}\right.$ ratio $\left.<80 \mathrm{~mm} \mathrm{Hg}\right)$.

- Uncompensated hypercapnia (pH, 7.2).

- Worsening hemodynamic status.

\section{Discharge Criteria to Step-down Unit or Ward}

- When patient's physiological status has stabilized and the need for ICU monitoring and care is no longer necessary

- Heart rate $<90 /$ minutes

- $\mathrm{SBP}>120 \mathrm{~mm} \mathrm{Hg}$ off vasopressors

- $\mathrm{RR}<20 /$ minutes

- Conscious, oriented

- Tolerating feeding

- Not needing any organ support treatment [continuous renal replacement therapy (CRRT), liver support, etc.]

\section{Take-home Points}

- Triaging of patients

- ICU admission and discharge policy to optimize bed utilization

\section{Equipment}

- Inventory checklist

- Personal protective equipment (PPE)

Considering the likelihood of an imminent increase in the number of patients with COVID-19 disease, the healthcare facilities should have a clear action plan to manage patients at surge capacity.

\section{Inventory Checklist}

Personnel

Medical, nursing, and ancillary staff requirement at surge capacity

Allocate staff members responsible for the care of COVID-19 patients. Ensure appropriate training, including the use of PPE among staff dedicated to the care of infected patients.

Plan for recruitment of additional staff at short notice in case of nonavailability of staff.

An established mechanism for expeditious staff training in case of an outbreak.

\section{Material (Annexure 5)}

- Stocks of hand hygiene material.

- Personal protective equipment.

- Ventilators.

- Infusion pumps, syringe pumps.

- Pharmacy supplies, including the use of novel therapies (hydoxychloroquine, lopinavir-ritonavir).

- Adequate supply of oxygen (central supply and portable cylinders). 
- Availability of disinfection facility for reusable material.

- Calculate the requirement of supplies for the projected period of time.

- Adequate supply of disinfection agents effective against coronaviruses.

- Adequate supply of garbage bins for disposal of potentially infectious waste.

- Facility to service and repair faulty equipment.

\section{Personal Protective Equipment}

The HCWs who care for critically ill patients with suspected or confirmed COVID-19 disease must use PPE. Operating room scrubs or full coveralls should form the first layer of protection beneath PPE. The PPE must include fluid-resistant but breathable gowns and gloves, goggles with side protection, hair covers or hoods, and preferably fit-tested N95 or equivalent like FFP3, KN95 etc. respirator masks. Caregivers should also wear disposable shoe covers or waterresistant shoes that can be decontaminated. Doffing of PPE should be carried out carefully, with diligent hand hygiene after removal. Ensure an adequate supply of the following PPE.

- Water-resistant gowns.

- Gloves.

- Surgical masks.

- Cap.

- Shoe covers.

- N95 masks.

- Visor.

- Goggles.

- Calculate the requirement for PPE for the projected period.

\section{Take-home Points}

- Equipment inventory.

- Procurement of enough PPEs as protection of HCWs is of utmost importance in this stressful exercise.

- Equal emphasis should be on quality of PPE.

\section{Logistics And CAPACITY}

\section{Airborne Infection Isolation Rooms Desirable}

Airborne infection isolation rooms are single-patient rooms at negative pressure relative to the surrounding areas and with a minimum of six air changes per hour (12 air changes per hour are recommended for new construction or renovation).

- Document that each AllR has been tested and is effective (e.g., sufficient air exchanges, negative pressure, exhaust handling) within the last month. The AlIR should be checked for negative pressure before occupancy.

- Air from these rooms should be exhausted directly to the outside or be filtered through a high-efficiency particulate air filter directly before recirculation.

\section{Environmental Cleaning}

- Facility should have a plan to ensure proper cleaning and disinfection of environmental surfaces in patient room.

- If environmental services personnel are given this responsibility, they should be appropriately trained and tested for fitness. All HCPs with cleaning responsibilities must understand the contact time for selected products. Facility should have a process or protocol to ensure shared or nondedicated equipment is cleaned and disinfected after use, according to the manufacturer's recommendations.

- Hypochlorite solution (1\% for disinfection and $0.5 \%$ for surface cleansing) should be available for use.

\section{Communication}

- Chain of command

- Communication components

\section{Chain of Command}

\section{Within the Hospital}

In a disaster, it is essential to have a standardized management structure, planning process, and personnel accountability. Personnel from different parts of the hospital (medical, nursing, administrative, support staff) must be able to communicate with standard terminology and integrate and coordinate efforts when confronted with a surge of patients. The hospital incident command system (HICS) must be developed and used by hospitals to tackle a disaster. The HICS enables structured communication within the ICU, cross-communication between departments and public health agencies, and effective communication and information flow and requests for personnel and equipment.

The top hospital leader (Director, Chief Executive Officer) is the incident commander. This position is absolutely required. He is advised by the identified medical and technical experts. Since intensive care is likely to be an important part of the response to COVID-19, a critical care specialist should be a part of this advisory group. This group also includes the public information officer and safety officer. Under the incident commander are section chiefs, including an operations section chief, a planning section chief, logistic sections chief, and a finance and administration chief.

The operations section chief looks after the inpatient clinical areas, including administrative and logistic support. Under the operations section chief, a medical director looks after all clinical care in inpatient and outpatient areas. An inpatient lead looks after all inpatient areas including the ICU.

\section{Within the ICU}

An ICU leadership team including medical, nursing, and other personnel should be created in each ICU in the hospital. A single ICU leader must be identified from among the multiple ICUs in a hospital. The responsibility of the ICU leader can be rotated with shifts depending on the circumstances.

\section{Communication}

Communication of critical care needs in a disaster (immediate and anticipated) is a key priority for the ICU leader during a disaster. Inadequate or confusing communication can magnify the problem. There must be an efficient process of communication within the ICU and hospital and outside the hospital. External communication includes communication with the media and the lay public. This is extremely important to convey the right messages and prevent undue panic.

\section{Internal Communication}

Communication within the incident command system and communication down the chain of command.

An example of effective communication is the SBAR method: Situation: Why am I calling? 
Background to the problem

Assessment of the patient's status

Response or recommendation: action required

\section{Communicating with Patients and Families}

Deliver information tactfully, accurately, promptly, and with empathy. Trained experts may be employed (e.g., social workers). Avoid speculative statements and complex language or medical jargon. Regular updates should be provided to the patients' relatives. All personnel must provide a common set of information regarding the patient's condition and prognosis to the family. The SPIKES approach is a useful method for discussion with the family and to break bad news:

$\mathrm{S}$-setting up the interview

P-assessing the patient's perception of the problem and patient's condition

I-obtaining the invitation to initiate the discussion

K-giving knowledge and information

E-addressing the emotions

S-strategy and summary

\section{Documentation and Patient Medical Records}

It is essential to maintain patient records at every step of the process during the patient's time in hospital. It may be necessary to have a system for tracking anonymous patients when large volumes of patients turn up.

\section{Communicating with the Media}

Hospitals and the media must work together effectively to provide accurate information and avoid speculation and opinionated commentary. The media must be given timely, accurate information on the number of patients and deaths, hospital and public health response, and other clinical and epidemiological characteristics of COVID-19.

\section{Communicating with other Hospitals and Healthcare Professionals}

When several public and private hospitals start treating COVID-19, it is important that hospitals and healthcare professionals share data and experiences on a frequent basis. Public health authorities must also be part of this effort, so that individual patient strategies and the societal response can be synchronized. Sharing information and learning from collective experience require collaboration and open communication between all levels of government, healthcare organizations, and frontline workers.

\section{Take-home Points}

- Use of digital media for communication with the patient's family

- It helps in reducing the traffic and exposure of HCWs

- Maintain communication with other hospitals and HCWs in this dynamic situation for sharing experience that might help in optimizing treatment

- Use of digital media by relatively stable patients to communicate with their relatives.

\section{Diagnostics-I}

- Radiological investigations

- Chest radiography
Chest radiography is complementary for assessing severity and disease progression in COVID-19 infection. Center for Disease Control and Prevention (CDC) does not recommend chest radiography for the diagnosis of COVID-19 infection because of the poor specificity with similar findings in other viral pneumonias such as H1N1 or influenza.

- Computerized tomography (CT) of the Chest

Not indicated in aiding diagnosis of COVID-19 infection, as recommended by $\mathrm{CDC}$.

The CT imaging shows bilateral ground glass opacities and or consolidation, peripheral patchy shadows involving more of the posterior lobes, rarely crazy paving appearance, nodules, septal thickening, and pleural effusion.

- Lung ultrasound

The observed lung ultrasound patterns include the following-

- Thickening of the pleural line with pleural line irregularity

- B lines-focal, multifocal, and confluent [correlating to the ground glass opacities on chest X-ray (CXR) and CT chest]

- Consolidations-multifocal small, extensive involvement with occasional mobile air bronchograms

- Appearance of $A$ lines during recovery phase

- Pleural effusions are uncommon.

Important recommendations for radiographers in handling COVID-19 cases:

- Radiography team should use appropriate PPE while performing radiography in a COVID-19 infected patient.

- Appropriate surface disinfectant should be used after imaging of a COVID-19 infected patient. The $\mathrm{CT} /$ magnetic resonance imaging gantries, $\mathrm{X}$-ray console, and ultrasound probes should be cleaned with recommended disinfectants.

- Consider using portable radiography units to prevent transport of infected patients.

\section{Take-home Points}

Radiography (CXR and $C T)$ are not required for diagnosis of COVID-19.

\section{Diagnostics-II}

- Sample collection and dispatch

- Transportation

\section{Collection of Samples}

Samples should be collected after donning PPE. Nasal and throat swabs should be collected as is done for influenza or any respiratory infection, with Dacron swabs and put inside the primary viral transport media tubes provided. Other clinical samples should be collected and sent whenever indicated. The temperature required to transport is as given in the chart by WHO.

\section{Diagnostics-III}

\section{Investigations}

Baseline

Complete hemogram, liver function test, renal function test, baseline electrocardiogram (ECG), chest radiograph, arterial blood gas (ABG) (if $\mathrm{SpO}_{2}<94 \%$ ). 
Follow-up: Complete hemogram, liver function test, renal function test are performed on alternate days. Other investigations as deemed appropriate by physicians.

\section{Risk factors and prognostic determinants}

Knowledge about the COVID-19 disease is still evolving. The mortality rates with the pandemic seem to be less than when compared to the earlier pandemics such as SARS and Middle East respiratory syndrome-related coronavirus (MERS-CoV). The mortality rates can be also be high due to early effect of the pandemic.

However, from the data that have emerged so far, severe form of the disease seems more likely among the elderly and the smokers. In addition, hypertension, diabetes, coronary artery disease, and chronic pulmonary disease also increased the odds for a more severe course with COVID-19.

Higher body temperatures were associated with more severe disease and higher fatality. In the Wuhan cohort, the following laboratory cutoffs appeared to indicate a poor prognosis

- Lymphopenia appeared to be a good predictor of severe disease and worse outcomes; a lymphocyte count of less than $2000 / \mathrm{mm}^{3}$ was associated with poorer outcomes. Similarly, a neutrophil/ lymphocyte (N/L) ratio greater than 2 was associated with higher mortality.

- $\mathrm{LDH}>245 \mathrm{U} / \mathrm{L}$.

- High-sensitive cardiac troponin $>28 \mathrm{ng} / \mathrm{mL}$.

- Prothrombin time $>16 \mathrm{~s}$.

- Serum ferritin $>300 \mathrm{mg} / \mathrm{L}$.

- D-Dimer $>1000 \mathrm{ng} / \mathrm{mL}$.

Baseline assessment of these laboratory parameters could help in prognostication. Mehta and Kataria from Gurugram managed 14 cases of COVID-19 and observed that the N/L ratio of $>1.9$ and C-reactive protein (CRP) of more than 100 were discriminatory in deciding the severity of the disease and complications (personal communication). In case of worsening patients, these values gradually worsened.

\section{Take-home Message}

- Samples should be collected after taking all precautions, including wearing the PPE kit

- Transportation should be done safely following the Indian Council of Medical Research (ICMR) guidelines

- The N/L ratio of more than 2 and progressive increase in CRP level indicate progressive disease.

\section{Sterilization}

- Cleaning and sterilization

- Cycling of patients

- Special precautions

- Reusage

- Alternatives for surge

\section{Cleaning and Sterilization}

- The minimum requirement of cleaning and disinfection recommended is at least once a day and more frequently if surfaces like benchtops or workbenches are visibly soiled.
- The decontamination procedure for cleaning a cubical or room housing suspected cases are given in Table A3.1, which is adopted from the guidelines of environmental disinfection NCDC, Delhi

- Doorknobs or ancillary objects touched by multiple people should be cleaned more frequently (every 3 to 4 hours).

- The concentration of disinfectants used per WHO and CDC is sodium hypochlorite $1000 \mathrm{ppm}(0.1 \%)$ for general surface disinfection and 10,000 ppm (1\%) for disinfection of large clinical samples or body fluid spills (laboratory biosafety guidance related to the novel coronavirus (2019-nCov). Interim guidance, February 12, 2020, WHO)

\section{Infection Control and Biomedical Waste Management}

- Waste disposal

- Reusage

\section{Biomedical Waste Management COVID-19 in ICU}

Management of waste that is suspected or known to contain or be contaminated with COVID-19 does not require special precautions beyond those already used to protect workers from the hazards they encounter during their routine job in solid waste and wastewater management.

\section{Special Attention}

- Suction tubing, catheter, ET tubes, ventilator tubings, urobag, intercostal drain (ICD) drain, central line, syringe: red bag

- ECG electrodes, glucose strip, cotton, gauze: yellow bag

- Mask: yellow bag

- Gloves: red bag

- Goggles: red bag

- Apron (disposable): yellow bag; linen apron: wash at laundry

- Shoe cover and cap: yellow bag

- Needles and sharp ampoules: puncture proof container

- Syringe cover, catheter cover, medicine cover and stationary: black bag

- ICD bottle, ampoules: blue bag

\section{Reprocessing of Consumables and Devices for COVID-19 in ICUs}

Reuse of single-use devices (SUDs) is not allowed currently in India.

However, with so many challenges on inventory and mass impact of pandemic, it is very likely that some SUDs such as highvalue consumables can be reused gradually under appropriate supervision.

Reprocessing of SUDs generally includes

- Disassembling

- Decontamination

- Cleaning

- Inspection

- Testing

- Packing

- Relabeling

- Sterilization 
and if necessary, refurbishing after they have been used on a patient for their intended purpose.

\section{Treatment Strategies}

- Basic outline

- Noninvasive support

- Ventilation support

- Extra-corporeal (EC) therapy

- Rescue strategies

- Supportive care

- Steroids

\section{Basic Outline}

Patients with COVID-19 requiring critical care should be managed in accordance with the management of acute hypoxemic respiratory failure due to other viral pathology and in line with the guidelines from WHO. Patients with suspected COVID-19 should be kept in isolation rooms. Patients with mild hypoxemic respiratory failure can be managed with supplemental oxygen. Noninvasive modes of ventilation or HFNC may be utilized in selected patients but under close observation. Patients with ARDS should be managed with fluid conservative strategies after initial fluid resuscitation, lung protective ventilation, empirical antibiotics to cover for suspected common bacterial pathogens, sedation with sedation-free intervals, thromboprophylaxis to prevent venous thromboembolism, and emphasis on nutrition. Patients with refractory hypoxemia may require prone positioning or ECMO.

\section{General Measures}

- All patients should be assessed for vital signs including hypoxemia and shock.

- Oxygen supplementation should be done for hypoxemic patients with initial target capillary oxygen saturation $\left(\mathrm{SpO}_{2}\right)$ of $>94 \%$. (Mandatory)

- For supplemental oxygen, a rebreather mask with an attached exhalation filter is preferred.

- After initial stabilization, oxygen supplementation should target an $\mathrm{SpO}_{2}$ of $>90 \%$ in adults and 92 to $95 \%$ in pregnant adults. (suggested)

- Patients requiring ET intubation should receive appropriate preoxygenation. Rapid sequence intubation should be performed if difficult airway is not expected. (mandatory)

- Endotracheal intubation should be performed by experienced individual with appropriate airborne infection control precautions. (mandatory)

- Patients with septic shock should receive fluid resuscitation along with vasopressor support. (mandatory)

- Norepinephrine should be the initial vasopressor; vasopressin or epinephrine may be used if the target mean arterial pressure is not achieved with norepinephrine. (suggested)

- All patients should receive empiric antibiotics to cover for all suspected organisms including influenza, as early as possible, preferably within the first hour. (mandatory)

- High flow nasal cannula (HFNC) and Noninvasive ventilation (NIV): Adults with COVID-19 and acute hypoxemic respiratory failure on conventional oxygen therapy, may be put on HFNC. Three ply face mask can be put on the canula covering chin to decrease the aerosolization.
In facilities, where HFNC is not available, NIV preferably with helmet as interface should be tried (to prevent aerosolization). In ARDS, NIV has limited utility but NIV support may be tried initially in selected patients under close observation in patients with mild to moderate ARDS, who are hemodynamically stable, alert, and able to handle respiratory secretions or in scenarios when invasive ventilators are not available.

Caution is advised when noninvasive ventilation or high flow nasal cannula are being used, as there is risk of aerosol formation, especially in patients with poorly fitting masks or interfaces. During use of NIV, there should be an HME filter between the mask and tubing. Leaks are to be minimized and the device should be switched off before removing the mask for feeding, toilet etc.

Patients on HFNC and NIV should be continuously and appropriately monitored for worsening of respiratory conditions and need of ET intubation, and intubation should not be delayed in such cases.

\section{Invasive Mechanical Ventilation}

Mechanical ventilation should be used by following a lung protective strategy ( 4 to $8 \mathrm{~mL} / \mathrm{kg}$ PBW).

Plateau pressure goal: $\leq 30 \mathrm{~cm} \mathrm{H}_{2} \mathrm{O}$.

Check Pplat ( 0.5 second inspiratory pause), at least every 4 hours and after each change in PEEP or VT.

If Pplat $>30 \mathrm{~cm} \mathrm{H}_{2} \mathrm{O}$ : decrease VT by $1 \mathrm{~mL} / \mathrm{kg}$ steps (minimum $=$ $4 \mathrm{~mL} / \mathrm{kg})$.

Consider the use of incremental $\mathrm{FiO}_{2} / \mathrm{PEEP}$ combinations such as shown below to achieve goal.

\section{Proning}

If patient does not show improvement in oxygenation, then proning should be tried, preferably early in the course of disease. It is usually associated with significant improvement in oxygenation status. On an average 16-18 hours of proning should be done. If there is a contraindication to proning, then recruitment manoeuvre can be tried. Follow thorough aerosol precautions while proning and take utmost precaution to avoid disconnection of the ventilator circuit.

\section{Rescue Strategies}

Veno-venous extracorporeal membrane oxygenation (VV-ECMO) has been used in ARDS with refractory hypoxemia and has been shown to improve oxygenation, albeit with variable outcomes in terms of mortality benefit. Appropriate patient selection and early application of ECMO are important to optimize outcomes. Veno-venous extracorporeal membrane oxygenation should be utilized early in eligible patients with severe ARDS and refractory hypoxemia, in specialized centers. (suggested)

\section{Steroids}

Systemic corticosteroids have been associated with decreased viral clearance in cases of MERS corona virus. No clinical benefit with possible delayed viral clearance was demonstrated in a small cohort of admitted COVID-19 patients with ARDS.

Systemic corticosteroids should not be routinely prescribed to critically ill patients with COVID-19, except when otherwise indicated, like associated acute exacerbation of chronic obstructive pulmonary disease or acute severe asthma or septic shock. (mandatory)

Inhaled steroids can be continued if indicated, in patients with COVID-19-related acute respiratory failure. (suggested) 


\section{Supportive Care}

All patients should receive standard supportive care as recommended for other critically ill patients with ARDS. This includes:

- Semi-recumbent position if not contraindicated.

- Judicious use of sedation.

- After resuscitation, conservative use of fluids.

- Daily sedation-free intervals, and assessment for weaning readiness.

- Standardized weaning protocols.

- Use of disposable ventilator circuits for each patient.

- Appropriate use of heat moisture exchanger or humidifier.

- Nonsteroidal anti-inflammatory drugs (NSAIDs) like ibuprofen are absolutely contraindicated.

- Closed suctions and HME filters with viral protection should be preferred to prevent aerosol spread.

- All inhaled medicines (bronchodilators) should preferably be given by metered dose inhalers (MDIs) to reduce the chances of aerosolization.

Pharmacologic thromboprophylaxis, if not contraindicated, should be given as a routine. If $D$-dimers value suddenly increase (more than doubled) or are more than $1000 \mathrm{ng} / \mathrm{dL}$, then consider therapeutic doses of LMWH. Mechanical thromboprophylaxis using intermittent pneumatic compression stockings can be used in cases where pharmacologic thromboprophylaxis is contraindicated.

- Optimal care to reduce the incidence of catheter-related blood stream infections.

- Early enteral nutrition (within 24 to 48 hours of admission) if not contraindicated.

- Frequent position change to prevent pressure sores.

- Use of histamine-2 receptor blockers or proton-pump inhibitors to prevent gastrointestinal bleeding.

- Early mobilization including passive and active rehabilitation exercises to prevent critical illness-related neuromuscular weakness.

- Tracheostomy in patients with prolonged mechanical ventilation.

\section{Treatment Strategies-II}

- Pharmacological treatment of COVID-19.

- Anticipated complicators and prognosticators.

\section{Pharmacological}

If flu is of unknown etiology, start oseltamivir $75 \mathrm{mg}$ twice daily in all adult patients with normal renal function [stop if H1N1/H3N2 reverse transcription polymerase chain reaction (RT-PCR) is negative]. Dosing should be adjusted per body weight in pediatric age-group.

Empirical antibiotics for the treatment of bacterial pneumonia, per guidelines, should also be added ( $\beta$ lactams along with macrolides).

While being admitted in ICU, hospital-acquired bacterial infections are common in invasively ventilated patients. In such patients, antibiotics should be added per the local microbiological flora.

\section{Protocol: Drug Management of COVID-19- Treatment}

- Currently, there is no effective drug treatment recommended for COVID-19 except supportive care. Not a single randomized controlled trial is available to recommend any specific drug for patients with suspected or confirmed COVID-19.

- Some of the drugs that are being used by the practitioners on the trial basis are remdesivir, lopinavir/ritonavir alone or with ribavirin, chloroquine/hydroxychloroquine, its active metabolite.

- Remdesivir has been found to act by inhibiting RNA synthesis. It has been demonstrated to have superior antiviral activity than lopinavir/ritonavir in vitro and animal study on MERS-CoV but the availability of the drug is a big challenge as it is available only through conditional access programs. ${ }^{1}$

- Lopinavir/ritonavir has been found to be effective in reducing the viral load. It was found to have a synergistic action with ribavirin in the management of MERS-CoV. In a recent trial from China, lopinavir/ritonavir combination was not found superior to placebo in critically sick patients. However, recently the ICMR allowed conditional use of this combination in the management of seriously ill COVID-19 patients having early organ dysfunction. The dosage recommended is lopinavir/ritonavir 400/100 mg BID for 10 days.

- Chloroquine/hydroxychloroquine have demonstrated their efficacy in various bench-side studies. Some of the initial human studies have also found that it causes significant reduction in viral PCR copies. The efficacy of both of these drugs have been shown in treatment as well as prophylaxis phases. The recent studies from France, though small in sample size, having technical flaws but still found to have significant rapid clearance. Chinese in vitro studies have also demonstrated the similar results. Dose recommended for hydroxychloroquine is $400 \mathrm{mg}$ BD for day 1 followed by $200 \mathrm{mg}$ BD from day 2 to day 4 . In the recent advisory issued by Indian Council of Medical Research, they have also recommended the use of hydroxychloroquine for prophylaxis in healthcare workers and close contacts (400 mg twice daily for day 1 followed by once weekly thereafter).

- In some patients, especially the ones with severe disease where cytokine storm is suspected, the interleukin-6 (IL-6) inhibitor tocilizumab has been tried with partial success. Before administrating this drug, IL-6 levels should be documented.

- There have been speculation regarding the impact of angiotensin converting enzyme inhibitors (ACEI) and angiotensin receptor blockers (ARB) on COVID-19 prognosis. However, American College of Cardiology/American Heart Association(ACC/AHA), Emergency Medical Association (EMA), European society of Cardiology (ESC) have recently issued a statement, advising to continue the use of ACEI and ARBs, if not contraindicated (like hypotension and acute kidney injury). We currently do not recommend their discontinuation in confirmed cases of COVID-19 but decision to start ACEls and ARBs should be made on shared basis.

\section{Chemoprophylaxis}

At present, infection control practices and PPE are the most important and recommended methods of prevention from COVID-19. 
Recently there is an emerging/at best suggestive evidence for the use of hydroxychloroquine as a chemoprophylactic agent. In the recent advisory issued by Indian Council of Medical Research (ICMR), it has recommended that health care workers, exposed to the confirmed cases of COVID19 as well as close of contact of the same be given chemoprophylaxis. Dose recommended for prophylaxis is $400 \mathrm{mg}$ twice daily for day 1 followed by a weekly dose of $400 \mathrm{mg}$ for seven weeks in case of health care workers and for 3 weeks for close contacts. (https://www.mohfw.gov.in/ pdf/AdvisoryontheuseofHydroxychloroquinasprophylaxisforSAR SCoV2infection.pdf).

\section{Cardiopulmonary resuscitation in COVID-19}

- "Crashes" should be avoided by close monitoring and anticipation aiming for an elective, unhurried intubation.

- The usual "code blue" should be replaced by a "protected code blue" to prevent unacceptable caregiver risk.

- Futility should be assessed and Do-Not-Attempt Resuscitation (DNAR) decisions taken in time. Meaningful outcomes in refractory critical illness and multiple organ failure is $<5 \%$.

- CPR should be undertaken in airborne isolation with a minimal team, and never without full PPE preferably donning a powered air-purifying respirator (PAPR).

\section{Take-home Points}

- Infection control practices continue to be the cornerstone

- Avoid, as far as possible, aerosolization procedures.

- Oxygen therapy can be delivered successfully by both high and low flow devices.

- Noninvasive ventilation should be used preferably with helmet. However, intensivist should have low threshold for intubation.

- Intubation should be done by experienced person preferably in one go, taking all aerosol-preventing precautions.

- ARDSnet protocol should be adhered to.

- Proning should be done in cases of difficult oxygenations.

- Use chloroquine/hydroxychloroquine as a first-line drug.

- Avoid NSAIDs (ibuprofen).

- Preferably continue with ACEI/ARB and take decision on shared basis

- Avoid CPR in case of Cardiopulmonary arrest.

\section{Monitoring}

Patients will be monitored daily for any clinical worsening and discharged after obtaining two consecutive negative RT-PCR results at least 24 hours apart from the oropharyngeal swabs.

\section{Outcome assessment}

- Requirement of mechanical ventilation

- Length of stay at hospital

- ICU-free days

- Mortality in ICU, hospital, and at 14, 28, and 90 days

- Side effects

- Acute pancreatitis

- Hepatic dysfunction

- Anaphylaxis reaction

- Adverse events and serious adverse events

- Viral RNA load in serial samples of nasopharyngeal and oropharyngeal samples.

\section{Anticipated Complications of COVID-19 infections}

Acute cardiac injury: This seems to be seen in 7 to $12 \%$ of cases. Fulminant myocarditis has also been reported. The description seems to be of patients who appear to be recovering from the respiratory illness succumbing to an arrhythmia. Heart failure was recorded in $52 \%$ of nonsurvivors and $12 \%$ of survivors in the Wuhan series. ${ }^{7}$

Acute kidney injury: This is seen in less than $10 \%$ of patients.

Disseminated intravascular coagulation: This complication has been reported in a very high percentage of nonsurvivors. Thrombocytopenia and coagulopathy were significant determinants of mortality in the Wuhan cohort.

\section{Post-ICU Care}

\author{
- Discharge \\ - Rehabilitation \\ - Follow-up
}

\section{Discharge Criteria for COVID-19 Infected Patients}

It is important to ensure that patient is noninfectious at the time of discharge or at the end of the quarantine. Following criteria can be used to discharge the COVID-19 infected patients depending upon whether they are symptomatic or not.

\section{Symptomatic Patients}

- Afebrile for 3 days

- Improved respiratory symptoms

- Nucleic acid tests (rRT-PCR) negative for SARS COV2 from two consecutive samples of nasopharyngeal or throat swabs at 24 hours' interval

There should be an interval of 7 days between the first and final tests before discharge (even if the patient clinically recovers earlier than 7 days).

\section{References}

1. Farmer JC, Wax RS, Baldisseri MR, ed., Preparing Your ICU for Disaster Response. Society of Critical Care Medicine.

2. Infection prevention and control when novel coronavirus infection is suspected. Interim Guidance. WHO (https://www. who.int/publications-detail/infection-prevention-and-controlduring-health-care-when-novel-coronavirus-(ncov)-infection-issuspected-20200125) Accessed on 16/03/2020.

3. COVID-19. Guidance for infection prevention and control in healthcare settings. Public Health England (https://assets.publishing.service. gov.uk/government/uploads/system/uploads/attachment_data/ file/872745/Infection_prevention_and_control_guidance_for_ pandemic_coronavirus.pdf).

4. Interim infection prevention and control recommendation for patients with COVID-19 in healthcare settings (https:// www.cdc.gov/coronavirus/2019-ncov/infection-control/controlrecommendations.html?CDC_AA_refVal=https $\% 3 \mathrm{~A} \% 2 \mathrm{~F} \% 2 \mathrm{Fwww}$. cdc.gov\%2Fcoronavirus\%2F2019-ncov\%2Fhcp\%2Finfection-control. html) Accessed on 16/03/2020.

5. The Australian and New Zealand Intensive Care Society Guidelines COVID-19. (https://www.anzics.com.au/wp-content/ uploads/2020/03/ANZICS-COVID-19-Guidelines-Version-1.pdf).

6. Arabi YM, Murthy S, Webb S. COVID-19: a novel coronavirus and a novel challenge for critical care. Intensive Care Med 2020. 1-4. DOI: 10.1007/s00134-020-05955-1.

7. Jin $Y$, Cai L, Cheng Z, Cheng H, Deng T, Fan YP, et al. A rapid advice guideline for the diagnosis and treatment of 2019 novel coronavirus 
(2019-nCoV) infected pneumonia (standard version). Military Med Res 2020;7(4). DOI: 10.1186/s40779-020-0233-6.

8. Bouadma L, Lescure F, Lucet JC, Yazdanpanah Y, Timsit JF, et al. Severe SARS-CoV-2 infections: practical considerations and management strategy for intensivists. Intensive Care Med 2020;46:579-582. DOI: https://doi.org/10.1007/s00134-020-05967.

9. Annexure-How to convert a room to negative pressure room.

10. Wang D, Hu B, Hu C, Zhu F, Liu X, Zhang J, et al. Clinical characteristics of 138 hospitalized patients with 2019 novel coronavirus-infected pneumonia in Wuhan, China. JAMA 2020;323(11):1061-1069.

11. Hosseiny M, Kooraki S, Gholamrezanezhad A, Reddy S, Myers L. Radiology perspective of coronavirus disease 2019 (COVID-19): lessons from severe acute respiratory syndrome and middle east respiratory syndrome. AJR Am J Roentgenol 2020. 1-5.

12. Yoon SH, Lee KH, Kim JY, Lee YK, Ko H, Kim KH, et al. Chest radiographic and $\mathrm{CT}$ findings of the 2019 novel coronavirus disease (COVID-19): analysis of nine patients treated in Korea. Korean J Radiol 2020;21(4):494-500.

13. Shi H, Han X, Jiang N, Cao Y, Alwalid O, Gu J, et al. Radiological findings from 81 patients with COVID-19 pneumonia in Wuhan, China: a descriptive study. Lancet Infect Dis 2020;20(4):P425-P434.

14. Song F, Shi N, Shan F, Zhang Z, Shen J, Lu H, et al. Emerging 2019 novel coronavirus (2019-nCoV) pneumonia. Radiology 2020;295(1): 210-217.

15. Peng $Q$, Wang $X$, Zhang L. Findings of lung ultrasonography of novel corona virus pneumonia during the 2019-2020 epidemic. Intensive Care Med 2020. DOI: 10.1007/s00134-020-05996-6.

16. Ruan Q, Yang K, Wang W, Jiang L, Song J. Clinical predictors of mortality due to COVID-19 based on an analysis of data of 150 patients from Wuhan, China. Intensive Care Med 2020. 1-3.

17. Liu J, Liu Y, Xiang P, Pu L, Xiong H, Li C, Zhang M, et al. Neutrophilto-lymphocyte ratio predicts severe illness patients with 2019 novel coronavirus in the early stage 10.1101/2020.02.10. 20021584.

18. Sheahan TP, Sims AC, Leist SR, Schäfer A, Won J, Brown AJ, et al. Comparative therapeutic efficacy of remdesivir and combination lopinavir, ritonavir, and interferon beta against MERS-CoV. Nat Commun 2020;11(1):222.

19. Chu CM, Cheng VC, Hung IF, Wong MM, Chan KH, Chan KS, et al. Role of lopinavir/ritonavir in the treatment of SARS: initial virological and clinical findings. Thorax 2004;59(3):252-256.

20. Chan KS, Lai ST, Chu CM, Tsui E, Tam CY, Wong MM, et al. Treatment of severe acute respiratory syndrome with lopinavir/ritonavir: a multicentre retrospective matched cohort study. Hong Kong Med J 2003;9(6):399-406.

21. Park SY, Lee JS, Son JS, Ko JH, Peck KR, Jung Y, et al. Post-exposure prophylaxis for middle east respiratory syndrome in healthcare workers. J Hospital Infect 2019;101:42-46.
22. Huang $C$, Wang $Y$, Li X, Ren $L$, Zhao J, Hu Y, et al. Clinical features of patients infected with 2019 novel coronavirus in Wuhan, China. Lancet 2020;395(10223):497-506.

23. Chen N, Zhou M, Dong X, Qu J, Gong F, Han, Y, et al. Epidemiological and clinical characteristics of 99 cases of 2019 novel coronavirus pneumonia in Wuhan, China: a descriptive study. Lancet 2020;395(10223):507-513.

24. Sun P, Qie S, Liu Z, Ren J, Li K, Xi J. Clinical characteristics of 50466 hospitalized patients with 2019-nCoV infection. J Med Virol 2020.

25. Zhou F, Yu T, Du R, Fan G, Liu Y, Liu Z, et al. Clinical course and risk factors for mortality of adult in patients with COVID-19 in Wuhan, China: a retrospective cohort study. 2020;395(10229):1054-1062. DOI: 10.1016/ S0140-6736(20)30566-3.

26. Xu L, Liu J, Lu M, Yang D, Zheng X. Liver injury during highly pathogenic human coronavirus infections. Liver Int 2020.

27. European Centre for Disease Prevention and Control. Checklist for hospitals preparing for the reception and care of coronavirus 2019 (COVID-19) patients. ECDC: Stockholm; 2020.

28. European Centre for Disease Prevention and Control. Discharge criteria for confirmed COVID 19 cases. When is it safe to discharge COVID 19 cases from the hospital or end home Isolation? ECDC: Stockholm; 2020.

29. World Health Organization. Report of WHO China Joint Mission Coronavirus Disease 2019. COVID 19, Geneva. Available from: https:// www.who.int/docs/default-source/coronaviruse/who-china-jointmission-on-covid-19-final-report.pdf.

30. Zhang W, Du R-H, Li B, Zheng X-S, Yang X-L, Hu B, et al. Molecular and serological investigation of $2019-n C o V$ infected patients: implication of multiple shedding routes. Emerg Microbes \& Infect 2020;9(1):386-389.

31. Zou L, Ruan F, Huang M, Liang L, Huang H, Hong Z, et al. SARS-CoV-2 viral load in upper respiratory specimens of infected patients. New England J Med 2020.

32. Bai $Y$, Yao L, Wei T, Tian F, Jin D-Y, Chen L, et al. Presumed asymptomatic carrier transmission of COVID-19. JAMA 2020.

33. Tay J-Y, Lim PL, Marimuthu K, Sadarangani SP, Min Ling Li, Peng Ang $\mathrm{BS}$, et al. De-isolating COVID-19 suspect cases: a continuing challenge. Clin Infect Diseas 2020. DOI: https://doi.org/10.1093/cid/ciaa17.

34. Coronavirus Disease 2019, World Health Organisation. https://www. who.int/emergencies/diseases/novel-coronavirus-2019/advice-forpublic.

35. https://www.esahq.org/esa-news/covid-19-airway-management/.

36. Schwartz J, King CC, Yen MY. Protecting health care workers during the COVID-19 coronavirus outbreak -lessons from Taiwan's SARS response. clinical infectious diseases: an official publication of the infectious diseases society of America 10.1093/cid/ciaa255.

37. Wax RS, Christian MD. Practical recommendations for critical care and anaesthesiology teams caring for novel corona virus (2019-nCoV) patients. Can J of Anaes 2020. 


\section{Annexure 1: Intubation Protocol}

1. Intubation should be carried out in a well-planned manner. All essential equipment must be in full readiness before you start.

2. Don adequate PPE including water-resistant gowns, gloves, fit-tested N95 masks or higher, goggle or face shields, and cap.

3. Not more than three healthcare personnel should be by the bedside to carry out intubation. One staff member should administer medications while the other assists with intubation and monitors the patient during the procedure.

4. A vasopressor infusion (e.g., noradrenaline, $4 \mathrm{mg} / 50 \mathrm{~mL}$ ) must be set up and ready to infuse in case of hypotension after the administration of anaesthetic agents.

5. Use a bag-mask system to pre-oxygenate to ensure maximal oxygen saturation prior to the administration of anaesthetic drugs.

6. Once the patient is asleep, suxamethonium $1.5 \mathrm{mg} / \mathrm{kg}$ or rocuronium $1.2 \mathrm{mg} / \mathrm{kg}$ is administered for muscle relaxation. Ensure adequate muscle relaxation before attempts at laryngoscopy.

7. A video laryngoscope is preferred if the operator is skilled, as it reduces the proximity of the operator to the airway compared to direct laryngoscopy.

8. It is important to get it right the first time; failed attempts are associated with increased risks of transmission of infection to staff. Intubate with a 7.0 or $7.5 \mathrm{~mm}$ ID endotracheal tube in female patients and 8.0 or $8.5 \mathrm{~mm}$ ID endotracheal tube in male patients.

9. Do not apply positive pressure before cuff inflation; this may cause a significant leak around the cuff and contamination.

10. Perform in-line suction to prevent the spread of aerosol; do not perform open suctioning.

11. If necessary, draw samples for virology during suctioning.

12. Carry out careful doffing of personal protective equipment after the procedure.

\section{Annexure 2: Proposed Management Algorithm}

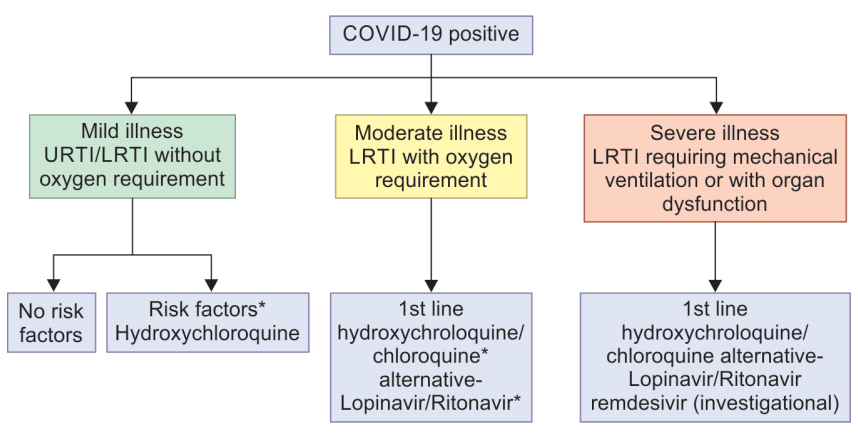

1. Hydroxychloroquine: $400 \mathrm{mg} \mathrm{BD}$ on day $1,200 \mathrm{mg} \mathrm{BD}$ day 2-4

2. Chloroquine: $300 \mathrm{mg}$ (elemental) twice daily for 10 days

3. Lopinavir/ritonavir: $400 \mathrm{mg} / 100 \mathrm{mg}$ PO BD for 10 days

4. Remdesivir: $200 \mathrm{mg}$ IV loading then $100 \mathrm{mg}$ IV OD for 10 days

*Risk factors: Chronic lung/heart/kidney/neurological disease, malignancy, immunodeficiency, long-term steroid use, pregnant lady, age $>60$ years, uncontrolled diabetes mellitus
\#Preferably avoid chloroquine/hydroxychloroquine with lopinavir/ritonavir in view of serious drug reactions

\section{Contraindications}

1. Porphyria

2. G6PD deficiency

3. Epilepsy

4. Heart failure

5. Recent MI

6. Uncontrolled arrhythmias

Adverse drug reactions

1. Hydroxychloroquine
a. Retinopathy
b. Skin rash
c. Hypersensitivity
d. Anemia/thrombocytopenia
e. Transaminitis.

2. Chloroquine

(i) Severe adverse reactions
a. QT prolongation, torsedes de pointes
b. Reduction in seizure threshold
c. Anaphylaxis or anaphylactoid reactions
d. Neuromuscular impairment
e. Neuropsychiatric disorders (delirium)
f. Pancytopenia
g. Neutropenia
h. Thrombocytopenia
i. Aplastic anemia
j. Hepatitis.

(ii) Common adverse reactions

k. Nausea, vomiting, diarrhea, abdominal pain

I. Visual disturbances, headache

m. Extrapyramidal symptoms.

3. Lopinavir/Ritonavir
a. Skin rash
b. Hypercholesterolemia
c. Increased serum triglycerides
d. Diarrhea, nausea, vomiting
e. Transaminitis.

4. Remdesivir: Adverse effects not known

\section{Annexure 3}

Guidance of adjustment of $\mathrm{FiO}_{2}$ and PEEP is shown in Table A3.1.

Table A3.1: PEEP and $\mathrm{FiO}_{2}$ combinations to be used for ventilating patients with ARDS

\begin{tabular}{|c|c|c|c|c|c|}
\hline $\begin{array}{l}\mathrm{FiO}_{2-}^{-} \\
\text {PEEP, } \\
\text { ARDS Net, } \\
\text { low PEEP }\end{array}$ & $\begin{array}{l}\mathrm{FiO}_{2}^{-} \\
\text {PEEP, } \\
\text { alveoli, } \\
\text { high PEEP }\end{array}$ & $\begin{array}{l}\mathrm{FiO}_{2-}^{-} \\
\text {PEEP, } \\
\text { ARDS Net, } \\
\text { low PEEP }\end{array}$ & $\begin{array}{l}\mathrm{FiO}_{2}-\mathrm{PEEP} \\
\text { alveoli, high } \\
\text { PEEP }\end{array}$ & $\begin{array}{l}\mathrm{FiO}_{2}-\mathrm{PEEP}, \\
\text { ARDS Net, } \\
\text { low PEEP }\end{array}$ & $\begin{array}{l}\mathrm{FiO}_{2-} \\
\text { PEEP, } \\
\text { alveoli, } \\
\text { high PEEP }\end{array}$ \\
\hline $0.3-5$ & $0.3-12$ & $0.6-10$ & $0.5-18$ & $0.9-14$ & \\
\hline $0.4-5$ & $0.3-14$ & $0.7-10$ & 0.5 to $0.8-20$ & $0.9-16$ & \\
\hline $0.4-8$ & $0.4-14$ & $0.7-12$ & $0.8-22$ & $0.9-18$ & \\
\hline $0.5-8$ & $0.4-16$ & $0.7-14$ & $0.9-22$ & 1.0 to $20-24$ & \\
\hline $0.5-10$ & $0.5-16$ & $0.8-14$ & 1.0 to $22-24$ & & \\
\hline
\end{tabular}




\section{Annexure 4: Guidance for Sample Collection}

Packaging and Transport (Figs A4.1 to A4.8)

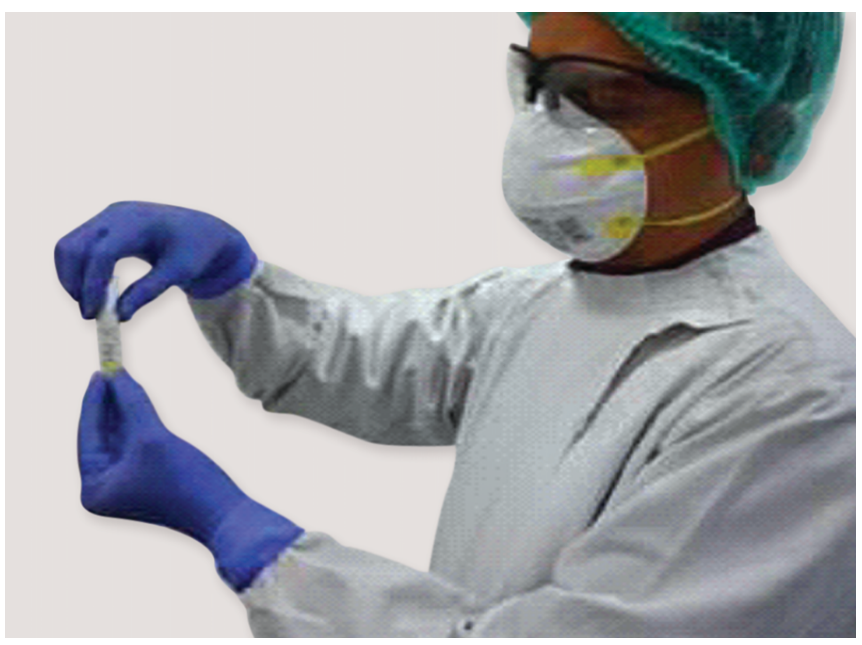

Fig. A4.1: Use PPE while collecting samples and handling the specimen tube

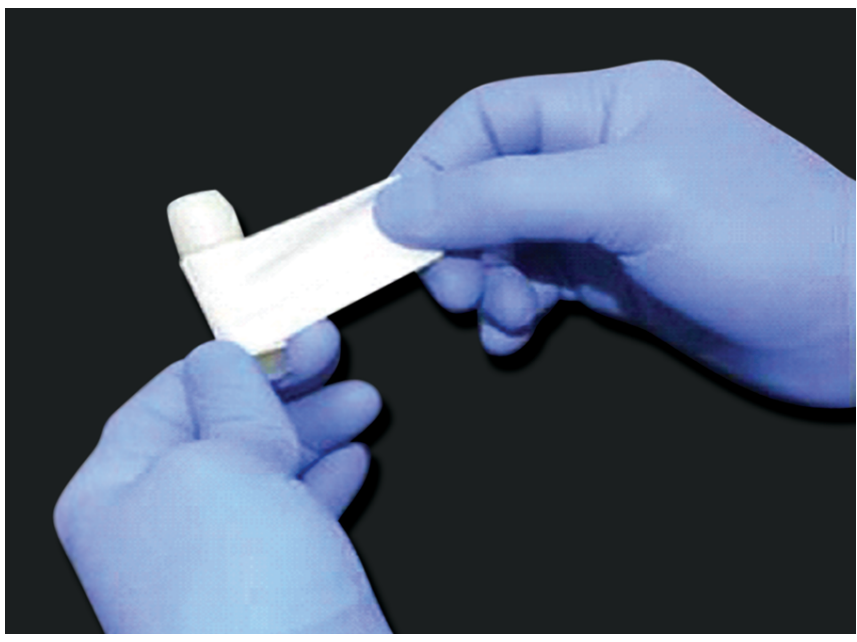

Fig. A4.3: Seal the neck of the sample vials using parafilm after the tube is labeled with the patient's accession number

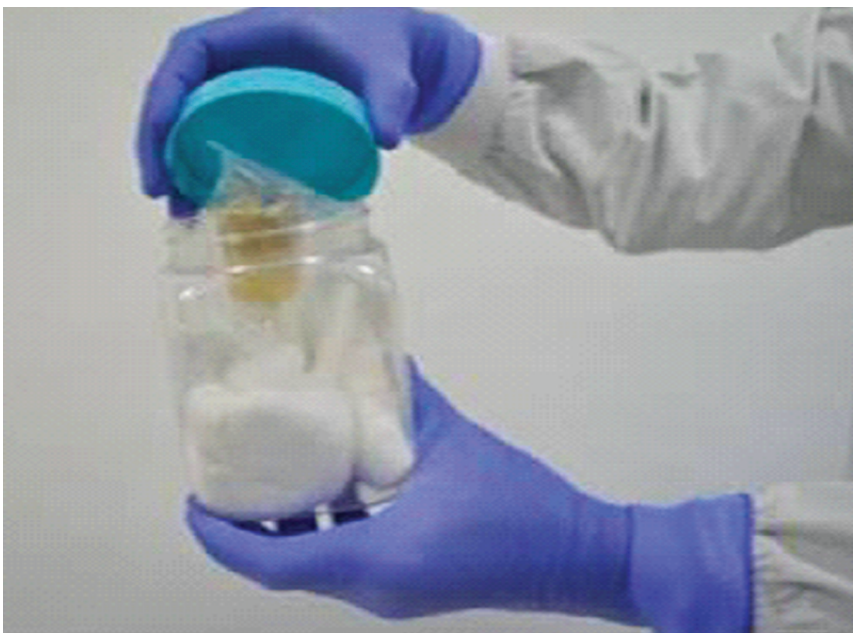

Fig. A4.5: The Ziploc pouch is kept in another plastic secondary container which is further secured

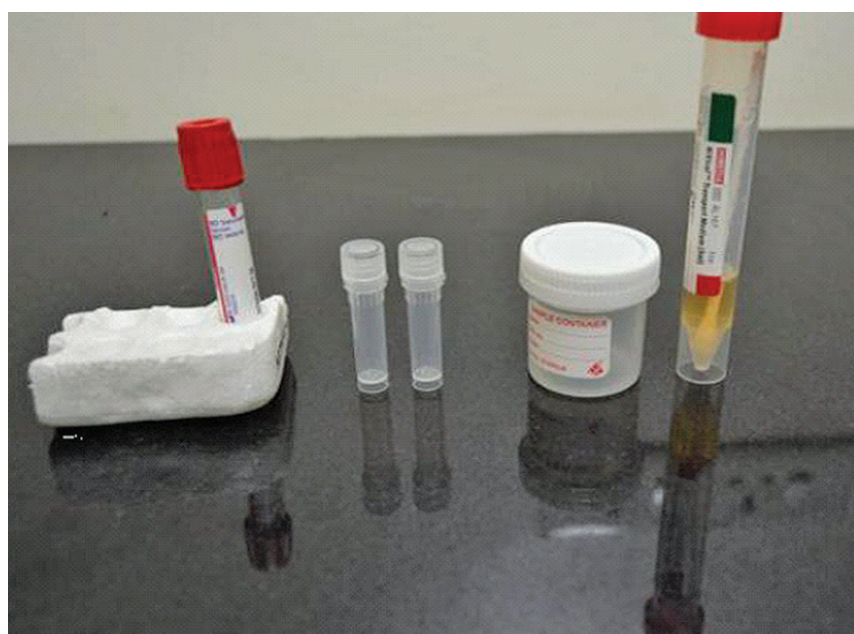

Fig. A4.2: Viral transport media with the swab handling of the specimen tube

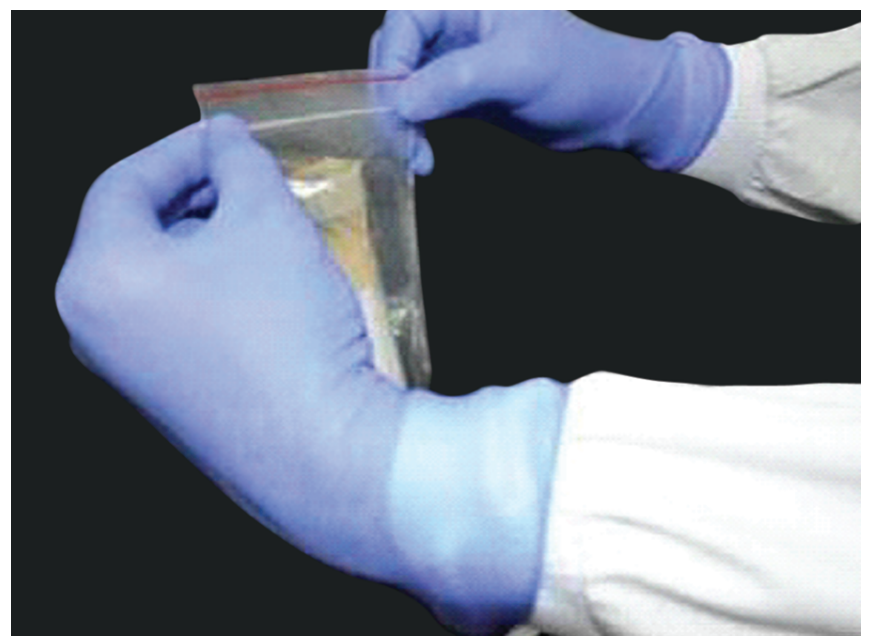

Fig. A4.4: Place the primary tube with the sample inside the Ziplock pouch covered with adsorbent material, e.g., cotton, and can be secured with a rubber band

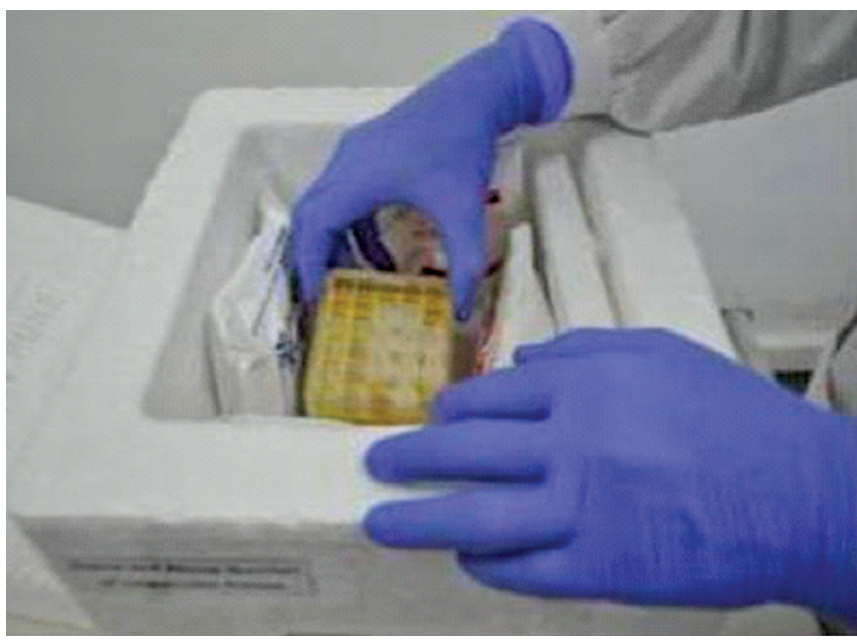

Fig. A4.6: The thermocol box is used as the outermost container and the secondary container is placed within it with frozen gel packs surrounding it 


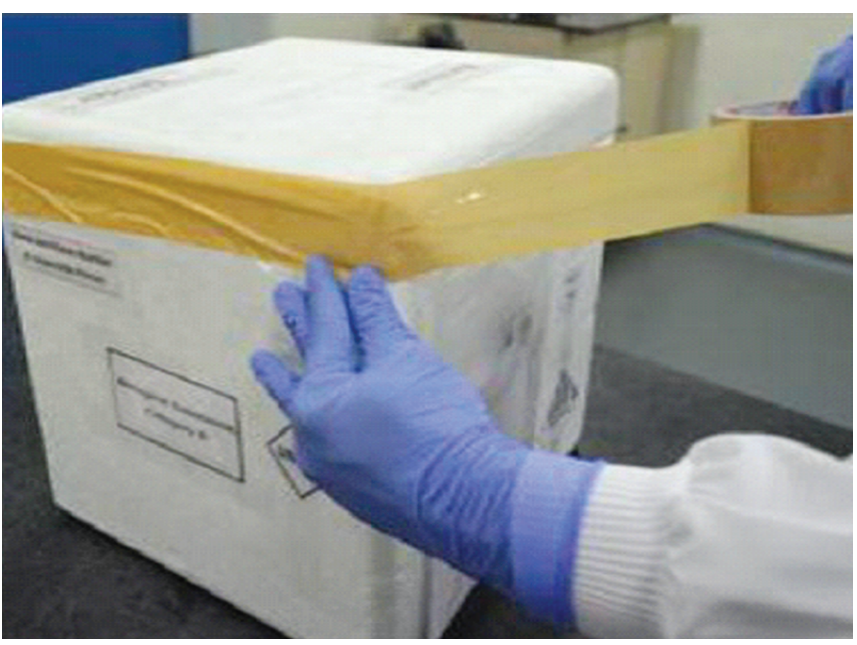

Fig. A4.7: Place the completed specimen referral form inside a Ziploc pouch and attach it with the outer container using a rubber band

\section{Annexure 5: Indications for Use and the Timing of Antiseptic Solutions}

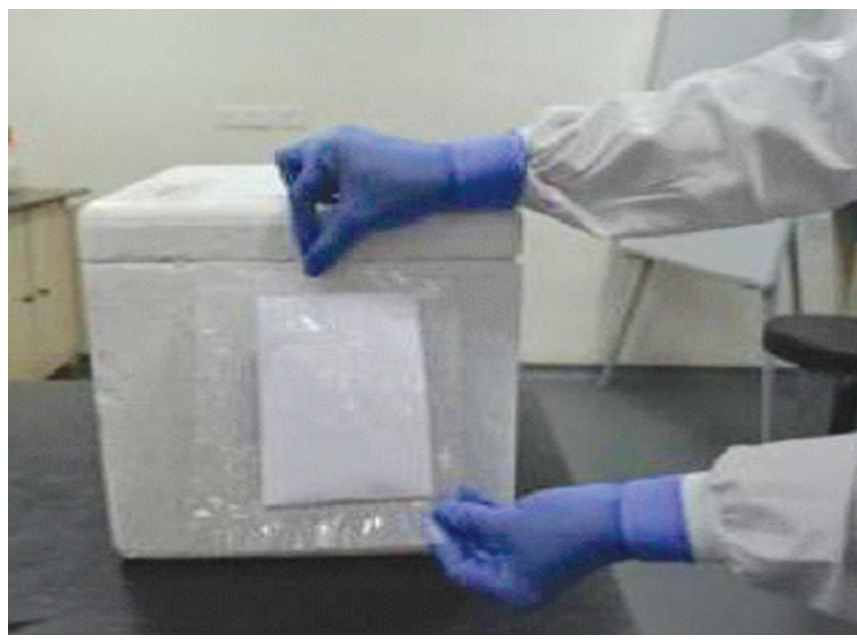

Fig. A4.8: Attaching the labels: Senders' address, contact number; Consignee's address/contact number. Biological substance - Category B; "UN 3373"; orientation label, handle with care, with a rubber band

\begin{tabular}{lll}
\hline Area/items & Item/equipment & Process \\
\hline $\begin{array}{l}\text { General clinical } \\
\text { areas }\end{array}$ & $\begin{array}{l}\text { Dust mops, mop (no broom } \\
\text { should be used for sweeping) }\end{array}$ & $\begin{array}{l}\text { Sweeping, } \\
\text { cleaning, daily } \\
\text { mopping }\end{array}$
\end{tabular}

Floors (clinical Detergent/sanitizer - hot areas) - daily water, sodium hypochlorite mopping (1\%).Three buckets (one with plain water, one with detergent solution and the third one with sodium hypochlorite (1\%)
Ceiling and walls
Sweeping tool, duster, bowl/ small bucket of soap solution, plain water

Care of mop
Method/procedure

Clinical area

- Sweep with the dust mop or damp mop to remove surface dust. Sweep under the furniture and remove dust from corners. Gathered dust must be removed using a hearth brush and shovel.

- The sweep tool should be cleaned or replaced after use.

- Prepare cleaning solution using detergent with warm water.

- Use the three-bucket technique for mopping the floor, one bucket with plain water, one with the detergent solution, and the third one with sodium hypochlorite (1\%).

- First mop the area with the warm water and detergent solution.

- After mopping clean the mop in clean water and squeeze it.

- Repeat this procedure for the remaining area.

- Mop area again using sodium hypochlorite $1 \%$ after drying the area.

- In between mopping if solution or water becomes dirty, change it frequently.

- Mop the floor starting at the far corner of the room and work toward the door.

- Clean the articles between cleaning.

- Note: Mopping should be done twice a day

Damp dusting - Damp dusting with a long-handled tool for the walls and ceiling done with very little moisture, just enough to collect the dust.

- Damp dusting should be done in straight lines that overlap on another.

- Change the mop head/cover when soiled.

- Note: Should be done once a week or after examining a suspect case

- Clean hot water and detergent solution, disinfect it with sodium hypochlorite, and keep for drying upside down. 
Contd...

\begin{tabular}{|c|c|c|c|}
\hline Area/items & Item/equipment & Process & Method/procedure \\
\hline $\begin{array}{l}\text { Doors and } \\
\text { doorknobs }\end{array}$ & $\begin{array}{l}\text { Damp cloth or sponge } \\
\text { squeeze mop, detergent }\end{array}$ & $\begin{array}{l}\text { Thorough } \\
\text { washing }\end{array}$ & $\begin{array}{l}\text { The doors are to be washed with a brush, using detergent and } \\
\text { water once a week (on one defined day); gently apply cloth to } \\
\text { soiled area, taking care not to remove the paint, then wipe with } \\
\text { warm water to remove excess cleaning agent. } \\
\text { - Doorknobs and other frequently touched surfaces should be } \\
\text { cleaned daily. }\end{array}$ \\
\hline Isolation room & $\begin{array}{l}\text { Detergent/sanitizer-warm } \\
\text { water, sodium hypochlorite } \\
\text { (1\%); three buckets (one } \\
\text { with plain water, one with } \\
\text { detergent solution, and } \\
\text { the third with sodium } \\
\text { hypochlorite (1\%) }\end{array}$ & $\begin{array}{l}\text { Terminal } \\
\text { cleaning }\end{array}$ & $\begin{array}{l}\text { Before cleaning an isolation room, liaise with infection control } \\
\text { room for details of any special requirements. Staff will be } \\
\text { instructed on specific cleaning procedures required with reference } \\
\text { to: } \\
\text { - safety uniform to be worn, } \\
\text { - chemicals or disinfectants to be used, } \\
\text { - also, if bed screen and shower screen are to be cleaned or } \\
\text { changed, refer cleaning in isolation rooms. }\end{array}$ \\
\hline $\begin{array}{l}\text { All clini- } \\
\text { cal areas/ } \\
\text { laboratories/ } \\
\text { wherever spill } \\
\text { care is required }\end{array}$ & $\begin{array}{l}\text { Sodium hypochlorite (1\%), } \\
\text { rag piece, absorbent paper, } \\
\text { unsterile gloves, spill care kit, } \\
\text { mop, hot water }\end{array}$ & $\begin{array}{l}\text { Blood and body } \\
\text { fluid spill care }\end{array}$ & $\begin{array}{l}\text { - Wear nonsterile gloves. } \\
\text { - } \text { For large spills, cover with absorbent paper/rag piece. } \\
\text { and carefully retrieve. Use a large amount of folded absorbent } \\
\text { paper to collect small glass splinters. Place the broken items into } \\
\text { the puncture-proof sharp container. } \\
\text { - Cover the spill with sodium hypochlorite (1\%) for } 10 \text { to } 20 \text { minutes' } \\
\text { contact time. } \\
\text { - Clean up spill and discard into infectious waste bin, and mop area } \\
\text { - } \text { with soap and hot water. } \\
\text { - Wash mop with detergent and hot water and allow it to dry. }\end{array}$ \\
\hline Stethoscope & Alcohol-based rub/spirit swab & Cleaning & - Should be cleaned with detergent and water. \\
\hline $\begin{array}{l}\text { Blood pressure } \\
\text { cuffs and cover }\end{array}$ & Detergent, hot water & Washing & $\begin{array}{l}\text { - Cuffs should be wiped with alcohol-based disinfectant; and } \\
\text { regular laundering is recommended for the cover. }\end{array}$ \\
\hline Thermometer & $\begin{array}{l}\text { Detergent and water, alcohol } \\
\text { rub individual thermometer } \\
\text { holder }\end{array}$ & Cleaning & $\begin{array}{l}\text { - Should be stored dry in individual holder. } \\
\text { - Clean with detergent and tepid water with alcohol rub in-between } \\
\text { patient use. } \\
\text { - Store in individual holder inverted. } \\
\text { - Preferably one thermometer for each patient. }\end{array}$ \\
\hline $\begin{array}{l}\text { Injection and } \\
\text { dressing trolley }\end{array}$ & $\begin{array}{l}\text { Detergent and water, absor- } \\
\text { bent paper or clean cloth }\end{array}$ & $\begin{array}{l}\text { Cleaning } \\
\text { (weekly) }\end{array}$ & $\begin{array}{l}\text { - Empty the fridge and store things appropriately. } \\
\text { - Defrost, decontaminate, and clean with detergent. } \\
\text { - Dry it properly and replace the things. } \\
\text { - Weekly cleaning is recommended. }\end{array}$ \\
\hline
\end{tabular}

\section{Annexure 6: II: Inventory Checklists}

\begin{tabular}{ll}
\hline \multicolumn{2}{l}{ Consumables } \\
\hline S. no. & Materials \\
\hline 1 & Antiseptic tincture $500 \mathrm{~mL}$ \\
2 & Acetone L.R-500 $\mathrm{mL}$ \\
3 & Ambu bag-adult \\
4 & Bipap vision system, tubing $6 \mathrm{ft}$ \\
5 & Culture bottle, plastic, sterile, $50 \mathrm{~mL}$ \\
6 & Cidex solution $2 \mathrm{~L}$ \\
7 & ECG gel $250 \mathrm{~g}$ \\
8 & Culture swabs, sterile: adult \\
\hline
\end{tabular}

Contd...

Consumables

S. no. Materials

9 Dressing material, Gamgee $(1.5 \mathrm{~cm})$ pad, sterile $35 \mathrm{~cm} \times$ $25 \mathrm{~cm}$

10 Dressing material, gauze, 12 Ply, sterile $5 \mathrm{~cm} \times 5 \mathrm{~cm}$ (pack of 10 nos)

11 Environmental disinfectant, Mikrozid HP10,1 L

12 Glucose test strips for blood - Accucheck Performa

13 Gloves surgical, nonsterile, nitrile, powder free, medium

14 Elastic adhesive bandage $-10 \mathrm{~cm} \times 4 \mathrm{~m}$

15 Garbage bags_large, black

16 Shoe cover, disposable, plastic

17 Hand rub $500 \mathrm{~mL}$ 
Contd...

\begin{tabular}{ll}
\hline Consumables \\
\hline S. no. & Materials \\
\hline 18 & Mask, surgical, three layered \\
19 & Pressure infusor $500 \mathrm{~mL}$ \\
20 & Sodium hypochlorite $20 \mathrm{~L}$ \\
21 & Surgical hand wash (Softcare Sensicare) $500 \mathrm{~mL}$ \\
22 & Surgical cap \\
23 & Thermal paper $50 \mathrm{~mm} \times 20 \mathrm{~m}$ (with graph) \\
24 & Tongue depressor, sterile (wooden) \\
25 & Vacuette (mini) EDTA K3 $1 \mathrm{~mL}$ \\
26 & Vacuette (mini) lithium heparin $1.0 \mathrm{~mL}$ \\
27 & Vacuette (mini) coagulation $1.0 \mathrm{~mL}$ \\
28 & Vacuette (mini) serum $1.0 \mathrm{~mL}$ \\
29 & Vacuette plasma, lithium heparin $4 \mathrm{~mL}$ \\
30 & Vacuette serum clotting accelerator $4 \mathrm{~mL}$ \\
31 & Vacuette coagulation sodium citrate $3.8 \% 2.7 \mathrm{~mL}$ \\
32 & Vacuette EDTA K2 $3 \mathrm{~mL}$ \\
33 & Surgical Tape - 2" \\
34 & Warming blankets (Bair Hugger M/c) - Full body
\end{tabular}

\section{Crash Cart}

\begin{tabular}{|c|c|}
\hline S. no & Medicine \\
\hline 1 & Inj. adrenaline 1:1000 \\
\hline 2 & Inj. atropine $0.6 \mathrm{mg} / \mathrm{mL}$ \\
\hline 3 & Inj. cordarone 150 mg/mL \\
\hline 4 & Inj. dexamethasone $4 \mathrm{mg} / \mathrm{mL}$ \\
\hline 5 & Inj. hydrocortisone 100 mg/vial \\
\hline 6 & Inj. lasix 10 mg/mL \\
\hline 7 & Inj. magnesium sulfate $50 \%$ \\
\hline 8 & Sterile water \\
\hline 9 & Inj. xylocard \\
\hline 10 & Mannitol (100 mL) \\
\hline 11 & Inj. neovec (fridge) \\
\hline 12 & Inj. midazolam 1 mL/mg (10 mL) \\
\hline 13 & Inj. noradrenaline \\
\hline 14 & $25 \%$ dextrose $100 \mathrm{~mL}$ \\
\hline 15 & Normal saline $100 \mathrm{~mL}$ \\
\hline S. no & IV fluids \\
\hline 1 & $5 \%$ dextrose \\
\hline 2 & Ringer lactate \\
\hline 3 & Normal saline \\
\hline \multicolumn{2}{|c|}{ Biomedical } \\
\hline S. no & Items \\
\hline 1 & Central monitor \\
\hline 2 & Patient monitor \\
\hline 3 & Portable monitor \\
\hline 4 & Cardiac output monitor \\
\hline 5 & Infusion pump \\
\hline 6 & Syringe pump (1:2) \\
\hline 7 & Ventilator \\
\hline
\end{tabular}

Contd...
Contd...

Biomedical

\begin{tabular}{cl} 
S. no & Items \\
\hline 8 & Ventilator portable
\end{tabular}

9 Oxygen flow meter

10 Oxygen flow meter twin

11 Oxygen analyzer

12 Air flow meter

13 Bair hugger

14 Low suction regulator

15 High suction regulator

16 High flow meter

17 ECG machine

18 ECHO machine

19 USG

20 Crash cart

21 Defibrillator (attached to crash cart)

22 BIPAP machine

23 Spotlight

24 Sequential compression device

25 Vibrator for chest physio

26 Pneumatic compressor

27 Ophthalmoscope

28 Bassinet bed (infant)

29 Incubator

30 Incubator portable

31 Glucometer

32 Suction jar

33 Nebulizer

34 Pacemaker single chamber

35 Pacemaker double chamber

36 Infant warmer with bed

37 Infant warmer

38 Infant warmer (portable)

39 CIPAP

40 Humidifier

41 Phototherapy

$42 \quad$ Light source

43 Pulse oxymeter

$44 \quad$ Weighing scale

45 Chemistry electrolyte analyzer

46 Thermal printer

47 Simulator

\section{Neopuff resuscitation system}

49 Body cooling system

50 EEG 8-channel system

51 Hand dryer

52 Jaundice meter

53 Patient cot

54 Patient trolley

55 Wheelchair

56 Gas outlet panel

57 ABG analyzer 


\begin{tabular}{ll}
\multicolumn{2}{l}{ Contd... } \\
\hline Biomedical \\
\hline S.no & Items \\
\hline 58 & Defibrillator \\
59 & Humidifier \\
60 & Incubator-neonatal \\
61 & Infusion pump \\
62 & Light source-fibroptic \\
63 & Low suction regulator \\
64 & Nebulizer \\
65 & Oxygen cylinder \\
66 & Oxygen flow meter \\
67 & Oxygen regulator \\
68 & Patient monitor \\
69 & Patient trolley \\
70 & Suction machine-electrical \\
71 & Syringe pump \\
72 & Ventilator \\
\hline
\end{tabular}

\section{Annexure 7: Care of Healthcare Workers}

In COVID-19 pandemic, care of healthcare workers is of utmost importance, as it is a stressful situation with many patients coming at the same time. This will lead to acute shortage of beds, with long working hours for HCWs, sleepless nights, caring for patients. There is an added stress of thinking about their own family members as everyone is at risk of acquiring disease and above all the risk of exposure to COVID-19 patients.

Before wearing PPEs, they should have had something to eat, visited washroom, and hydrate themselves.

- One should wear the right PPEs that is meant for airborne and fomite infections with hood, goggles, visor (especially during aerosol-generating procedures),

- Before entering, it should be checked by someone that PPE is being put in right way and all the skin surfaces are covered.

- Doffing should be done cautiously and spraying of doffed clothing with hypochlorite solution should be done immediately

- Surface disinfection in the area where COVID-19 patient is being treated should be conducted at regular intervals

- To avoid burnout, batches should be created and scheduled with rest period in-between.

- Adequate arrangements for stay of HCWs attending the COVID-19 patients, as it is preferable that HCWs attending COVID-19 patients should stay back in hospital or isolation facilities, such as hotels and hostels. Such isolations should continue for the period when they are attending to COVID19 patients. Following this, they should be advised home isolation for 14 days if asymptomatic and if symptomatic should be isolated in hospital as per severity.
- If at all the HCW decides to go back home, he or she should take utmost care to wash hands and preferably have bath before going home.

- At home, practice self-isolation, preferably use separate room and bathroom, wash his or her clothes separately, use separate utensils.

- Hydroxychloroquine should be offered to all the HCW attending the COVID-19 patients.

\section{Annexure 8}

Standard Precautions to be followed by healthcare workers while handling dead bodies of COVID-19 patients. [Per the advisory from the Government of India (GOI), Ministry of Health and Family Welfare Directorate General of Health Services (EMR Division)]

- Adequate hand hygiene and use of PPE (e.g., water-resistant apron, gloves, masks, eyewear) before handling of body.

- Utmost caution while handling sharps.

- Disinfect the bag housing dead body and the instruments and devices used on the patient with $1 \%$ sodium hypochlorite.

- Remove all the tubings and drains. Puncture holes be cleaned with $1 \%$ sodium hypochlorite.

- Oral and nasal orifices should be plugged adequately to prevent leakage of body fluids.

- Disinfect the linen, and clean and disinfect the environmental surfaces.

- If the family wishes to have a look at the body, with adequate precautions they may be allowed to do so.

- Body should be placed in leak proof plastic bag.

- Body can be stored in mortuary at temperature $4^{\circ} \mathrm{C}$.

- Care of linen and equipment

- All linen should be put in biohazard bag and spray the outer surface with $1 \%$ sodium hypochlorite.

- Environmental surfaces, instruments, and transport trolleys should be properly disinfected with $1 \%$ hypochlorite solution.

- After removing the body, the chamber door, handles, and floor should be cleaned with $1 \%$ sodium hypochlorite solution.

- Per the guidelines by GOI, embalming should not be allowed

- Transportation

- The body can be transported in secured bag and the vehicle used for transport should be decontaminated with $1 \%$ sodium hypochlorite.

- Cremation/burial.

- Large gathering for last rites should be avoided.

- Crematorium/burial staff should be sensitized that body in secured plastic bag does not poses additional risk factor.

- Family member may be allowed to have a look by unzipping the bag.

- Kissing, hugging, and bathing of the dead body should not be allowed.

- After cremation/burial, adequate hand washing should be performed by family members and staff.

- Ash does not pose any risk and can be collected for last rites. 


\section{Annexure 9: Team Plan for COVID-19 (One of the Tempalates) Set 1: Screening, triage and admission}

\begin{tabular}{|c|c|c|c|c|c|}
\hline & & Team A & Team B & Team C & Control room \\
\hline \multicolumn{2}{|c|}{ Responsibilities } & $\begin{array}{l}\text { Screenir } \\
\text { Admissi }\end{array}$ & $\begin{array}{l}\text { atients, } T \\
\text { fting to i }\end{array}$ & ICU investigations. & $\begin{array}{l}\text { Looking for adequacy of manpower, supplies, } \\
\text { coordination between all concerned, data } \\
\text { collection }\end{array}$ \\
\hline Consultants & $\begin{array}{l}\mathrm{PCCM} \pm \text { Medicine, } \\
\text { Respiratory medicine, } \\
\text { Psychologist (if available) }\end{array}$ & & & & $\begin{array}{l}\text { Hospital administrator, Nodal person for } \\
\text { COVID, Nursing superintendent, Consultant } \\
\text { laboratory medicine/Microbiology, } \\
\text { intensivist, Stores and Procurement, Head of } \\
\text { Emergency Services }\end{array}$ \\
\hline $\mathrm{SR} / \mathrm{JR}$ & $\begin{array}{l}\text { Medicine, Respiratory } \\
\text { medicine, PSM (if } \\
\text { available), Surgery, } \\
\text { Pediatrics }\end{array}$ & & & & \\
\hline Nursing & $\begin{array}{l}\text { A\&E, Medicine, } \\
\text { Respiratory medicine }\end{array}$ & & & & \\
\hline \multicolumn{6}{|l|}{$\begin{array}{l}\text { Bearer/ } \\
\text { general duty } \\
\text { attendants }\end{array}$} \\
\hline \multicolumn{2}{|l|}{ Sweeper } & & & & \\
\hline
\end{tabular}

\section{Set 2: Admitted patients and ICU}

\begin{tabular}{|c|c|c|c|c|c|}
\hline & & Team A & Team B & Team C & Control room \\
\hline \multicolumn{2}{|c|}{ Responsibilities } & \multirow{6}{*}{\multicolumn{3}{|c|}{$\begin{array}{l}\text { Treatment plan, Airway, Oxygenation, Medication, } \\
\text { Ventilation }\end{array}$}} & \multirow[t]{6}{*}{$\begin{array}{l}\text { Looking for adequacy of manpower, supplies, } \\
\text { coordination between all concerned, data } \\
\text { collection }\end{array}$} \\
\hline Consultants & $\begin{array}{l}\text { PCCM, Anesthesia, } \\
\text { Medicine, Respira- } \\
\text { tory medicine or any } \\
\text { Department having ICUs }\end{array}$ & & & & \\
\hline $\mathrm{SR} / \mathrm{JR}$ & $\begin{array}{l}\text { PCCM, Anesthesia, } \\
\text { Medicine, Respiratory } \\
\text { medicine, Pediatrics, } \\
\text { Departments having ICU }\end{array}$ & & & & \\
\hline Nursing & Trained in Intensive Care & & & & \\
\hline \multicolumn{2}{|l|}{ Bearer } & & & & \\
\hline \multicolumn{2}{|l|}{ Sweeper } & & & & \\
\hline
\end{tabular}

Team A works for 7 days $\rightarrow$ while team $B$ is standby $\rightarrow$ daily briefing among all $A+B$

Team $B$ works 8-14 days $\rightarrow$ while team $C$ is standby $\rightarrow$ daily briefing among all $B+C$

Team B works 15-21 days $\rightarrow$ while team $A$ is standby $\rightarrow$ daily briefing among all $C+A$

All teams to work in 4 batches of morning/evening/night/off protocol

\section{Steps for High Morale of Teams}

\section{A dedicated roster}

- Provision of clean scrubs for HCW to change into before duty; showering facilities at the end of shift

- Education and re-education on personal protective equipment and use of powered air-purifying respirators if available

- 2-week off-duty observation period after every period of ICU and isolation ward duties

- Mandatory reporting of twice daily temperature monitoring by all HCW

- Provision of thermal scanners at the doorstep to screen for fever

- Special provision of meals and drinks to boost morale; laundry service for used scrubs

- Regular updates of the local situation and status by Institutional leadership

- Provision for comfort of team-Television, internet, music in surroundings, rest area for HCW

- Appropriate media coverage of HCW at the frontline to increase empathy and reduce stigmatization 


\section{Annexure 10: Specifications of PPEs}

\section{For Masks (N-95 Masks or Equivalent)}

1. Shape that will not collapse easily

2. High filtration efficiency

3. The mask manufacturer should specify the filter medium used and the capacity of filter medium, should be $94 / 95 \%$ efficiency for filtering $0.3-\mu \mathrm{m}$ water aerosol

4. Good breathability with expiratory valve

5. Quality compliant with standards for particulate respirator that can be worn with full-face shield

6. The mask should conform to any of the following certifications/ class/standards
a. USA-N95 (NIOSH-42C FR84)
b. European Union-FFP2 (EN 149-2001)
c. Germany-KN 95 (GB2626-2006)
d. Australia and New Zealand-P2 (AS/NZ 1716:2012)
e. South Korea-Korea 1st Class (KMOEL-2017-64)
f. Japan-DS (Japan JMHLW-Notification 214, 2018)

\section{Coverall (Medium and Large) or Gowns}

Transmission of virus is in two forms only (1) droplet - size $>5 \mu \mathrm{m}$, distance traveled is about $1 \mathrm{~m}$ only then droplets fall down on floor, (2) aerosol - size $<5 \mu \mathrm{m}$, but always more than $0.3 \mu \mathrm{m}(90 \%$ aerosol size is $>0.5 \mu \mathrm{m})$. HCW need protection from droplet and aerosol and NOT the virus per se with the laboratory size of $0.125 \mu \mathrm{m}$

1. Impermeable to blood and body fluids [Meets ISO 16603 class 3 exposure pressure, or equivalent (synthetic blood penetration resistance test)]

- Single use

- Avoid culturally unacceptable colours e.g., black

- Light colours are preferable to better detect possible contamination

- Thumb/finger loops to anchor sleeves in place

2. The coveralls should be taped at the seems to prevent fluid/ droplets/aerosol entry

3. Breathability of the entire fabric use for single piece PPE or double piece PPE must have the following range of AP and WVTR/MVTR:

a. Air permeability (L/ $\mathrm{m}^{2} /$ minute): $100-150$

b. Water/moisture vapor transmission rate-WVTR/MVTR (g/ $\mathrm{m}^{2} /$ day): $400-500$

c. Manufacturers must provide the specifications of the nonwoven fabric used for the manufacturing of PPE.
4. The preferred fabric for coveralls should be one or the other non-woven fabric which meets on the above criteria.

\section{Goggles}

1. Transparent glass, zero power, well fitting, covered from all sides with elastic band or adjustable holder

2. Good seal with the skin of the face

3. Flexible frame to easily fit all face contours without too much pressure

4. Accommodates for prescription glasses

5. Fog and scratch resistant

6. Quality compliant with below standards or equivalent:

a. EU standard directive 86/686/EEC, EN166/2002

b. ANSI/SEAZ87.1-2010

\section{Gloves}

1. Nitrile, non-sterile, powder free

2. Outer gloves preferably reach mid-forearm (minimum $280 \mathrm{~mm}$ total length)

3. Quality compliant with the below standards or equivalent;

4. EU standard directive $93 / 42 /$ EEC Class I, EN455

5. EU standard directive $89 / 686 /$ EEC category III, EN374
a. ANSI/SEA 105-2011
b. ASTM D6319-10

\section{Face Shield}

1. Made of clear plastic and provides good visibility

2. Adjustable band to attach firmly around the head

3. Fog resistant (preferable)

4. May be reusable

5. Quality compliant with the below standards, or equivalent:

a. EU standard directive 86/686/EEC, EN166/2002

b. ANSI/SEA Z87.1-2010

Reference: Ministry of Health and Family welfare, DGHS, Delhi(emergency medical relief)-guidelines on rational use of personal protective equipment.

\section{ACKNOWLedgment:}

Prof Arvind Baronia,

Professor \& Head

Department of Critical Care Medicine

SGPGI, Lucknow

Central Helpline Number for Corona-Virus: - +91-11-23978046 Helpline Numbers of States \& Union Territories (UTs) 